\title{
Article \\ The "Fish Tank" Experiments: Metacognitive Awareness of Distinctions, Systems, Relationships, and Perspectives (DSRP) Significantly Increases Cognitive Complexity
}

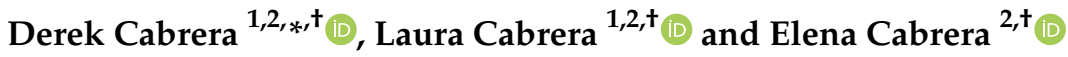 \\ 1 Jeb E. Brooks School of Public Policy, Cornell Institute for Public Affairs, SC Johnson College of Business, \\ Cornell University, Ithaca, NY 14850, USA; lac19@cornell.edu \\ 2 Cabrera Research Lab, Ithaca, NY 14850, USA; eac272@cornell.edu \\ * Correspondence: dac66@cornell.edu \\ + These authors contributed equally to this work.
}

check for updates

Citation: Cabrera, D.; Cabrera, L.;

Cabrera, E. The "Fish Tank"

Experiments: Metacognitive

Awareness of Distinctions, Systems,

Relationships, and Perspectives

(DSRP) Significantly Increases

Cognitive Complexity. Systems 2022

10, 29. https://doi.org/10.3390/

systems 10020029

Academic Editor: William T. Scherer

Received: 26 November 2021

Accepted: 19 January 2022

Published: 4 March 2022

Publisher's Note: MDPI stays neutral with regard to jurisdictional claims in published maps and institutional affiliations.

Copyright: (C) 2022 by the authors. Licensee MDPI, Basel, Switzerland. This article is an open access article distributed under the terms and conditions of the Creative Commons Attribution (CC BY) license (https:// creativecommons.org/licenses/by/ $4.0 /)$.

\begin{abstract}
In the field of systems thinking, there are far too many opinioned frameworks and far too few empirical studies. This could be described as a "gap" in the research but it is more like a dearth in the research. More theory and empirical validation of theory are needed if the field and the phenomenon of systems thinking holds promise and not just popularity. This validation comes in the form of both basic (existential) and applied (efficacy) research studies. This article presents efficacy data for a set of empirical studies of DSRP Theory. According to Cabrera, Cabrera, and Midgley, DSRP Theory has equal or more empirical evidence supporting it than any existing systems theories (including frameworks, which are not theories). Four separate studies show highly statistically relevant findings for the effect of a short (less than one minute) treatment of D, S, R, and P. Subjects' cognitive complexity and the systemic nature of their thinking increased in all four studies. These findings indicate that even a short treatment in DSRP is effective in increasing systems thinking skills. Based on these results, a longer, more in-depth treatment-such as a one hour or semester long training, such is the norm-would therefore likely garner transformative results and efficacy.
\end{abstract}

Keywords: metacognition; universals; cognitive complexity; systems thinking; DSRP Theory; material complexity; systems science

\section{Introduction}

There is currently a dearth ${ }^{1}$ of empirical research into what systems thinking is and how it can be improved. As a hypothetical example, a team of observers trained only in the current literature on systems thinking and shown one hundred instances of thinking would find it futile to determine empirically how many of those one hundred instances were instantiations of systems thinking. Nor would they be able to measure to what degree the instances were or were not systems thinking. In other words, we use the term systems thinking as if we know what it is and can reasonably measure it, when we cannot. Even more, many of the claims about systems thinking or definitions for it are not empirical to begin with, in that they have not or cannot be validated.

Cabrera [1] expanded on systems thinking theoretically by proposing [1-6] DSRP Theory, which details four empirical patterns of both mind and nature: identity-other Distinctions (D). part-whole Systems (S), action-reaction Relationships (R), and point-view Perspectives $(\mathrm{P})$. Each pattern is composed of two elements. In its simplest form, DSRP Theory states: 
"the ways $\overbrace{\begin{array}{c}\text { information } \\ \text { Relationships }\end{array}}^{\text {that which is Organized }}$ is / is not $\overbrace{\begin{array}{c}\text { bounded } \\ \text { Perspectives }\end{array}}^{\text {Distinctions }}, \overbrace{\text { arranged }}^{\text {Systems }}$

and $\overbrace{\text { interconnected }}^{\text {from }} \overbrace{\text { frames of reference }}^{\text {determines }}$ $\overbrace{\text { what actually exists }}^{\text {Material Complexity (Nature) }}$ and $\overbrace{\text { what we think exists. }}^{\text {Cognitive Complexity (Mind) }}$

But DSRP Theory entails more than is relayed by this simplified statement [1,7-10]. Cabrera, Cabrera, and Midgley [2], discussing DSRP Theory has launched a fourth wave in the field of systems thinking, pointed out that:

Since Cabrera's first writings, we now have the benefit of over 20 years of hindsight on the possible start of a fourth wave (which is as long as the gap between the first and second waves, and twice as long as the gap between the second and third waves). During those years, we have seen considerable testing of Cabrera's DSRP Theory, including: (1) a burgeoning amount of empirical evidence (at least as much as has been offered in the previous waves); (2) substantial private sector funding to develop tools for systems thinking; (3) substantial public funding for research; (4) a substantial peer review and publication history, sizeable citation histories, including several special issues dedicated to DSRP; (5) considerable public exposure and critique; (6) public adoption; (7) high attendance annual conferences; institutional recognition and support; and (9) as yet, few competitor theories (at least, none that have been explicated and communicated to the same degree).

Cabrera details DSRP Theory in a primer [11] and also elaborates on the the literature and evidence base for DSRP Theory $([1,3,11-18])$ as well as, specifically, the literature on: identity-other Distinction making (D) [5,19-89]; part-whole Systems (S) $[1,5,21,48$, 49,57,59-105] action-reaction Relationships (R) [1,5,21,57,59-89,105-120]; and, point-view Perspectives (P) [5,12,57,59-89,121-153].

Cabrera's 2021 review of research [12] builds upon two previous literature reviews [1,6], constitutes a proverbial "tip of the iceberg", and is part of an accumulating body of evidence in support of the predictions made by DSRP Theory generally. Figure 1 shows the methodological distribution of this research and Figure 2 shows the distribution of these studies across DSRP pattern.

\section{K-MMM Analysis}

$\mathrm{N}=128$

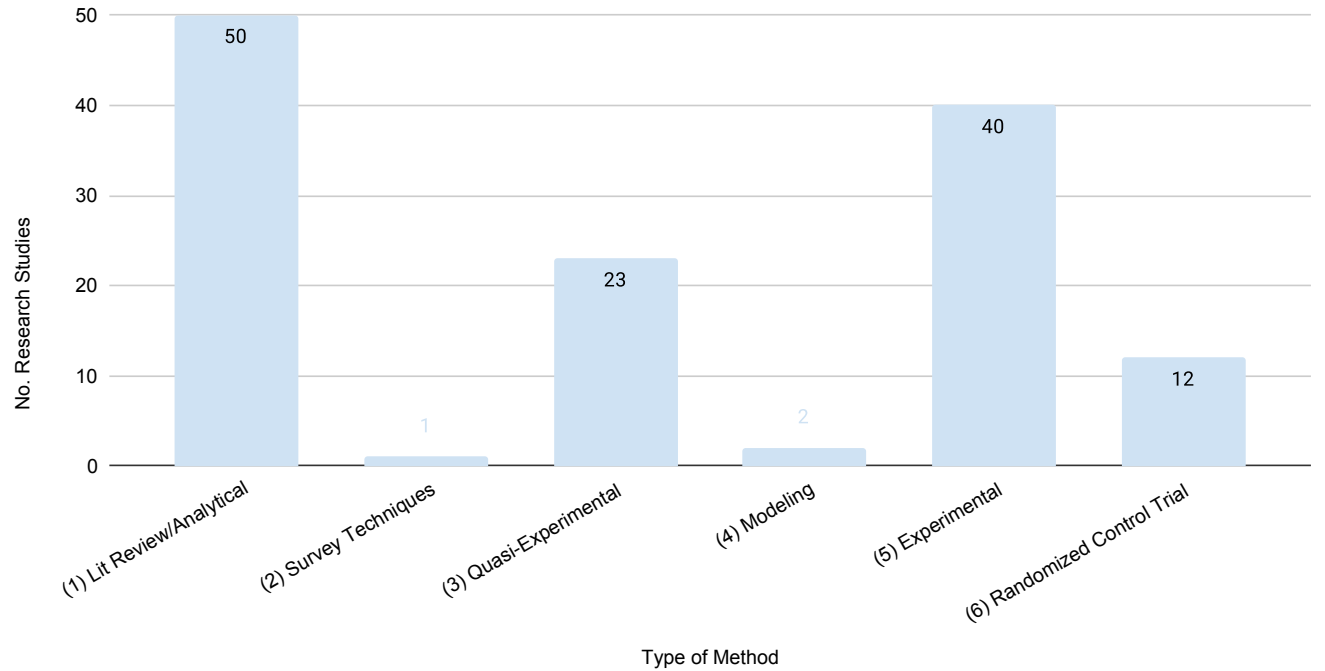

Figure 1. Knowledge-Method Matching Matrix (KMMM) analysis of empirical findings in DSRP across the disciplines. 


\section{Research by Pattern (DSRP) \\ $\mathrm{N}=128$}

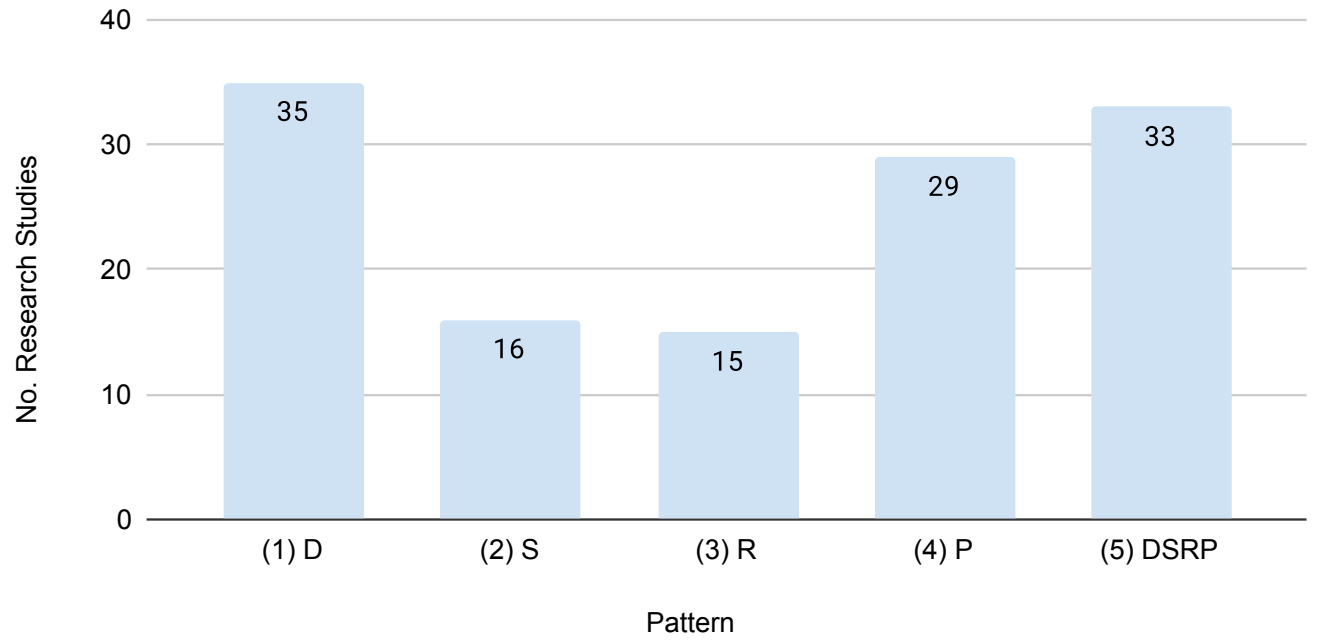

Figure 2. K-MMM analysis of empirical studies by DSRP pattern.

The Importance of Metacognition in Systems Thinking

Cabrera et al. (2021) [154] writes, "An important aspect of systems thinking is the act of metacognition. The process of deliberately structuring one's thoughts using the four building blocks of cognition (D, S, R and P) requires awareness of, or thinking about, one's own thinking, or metacognition" (p. 11, [154]). Systems thinking is synonymous with cognitive complexity. Thus, DSRP Theory further stipulates that awareness of the D, $S, R$, and P structures (i.e., "metacognition of DSRP") can increase one's effectiveness in thinking about systems, modeling systems, or in increasing cognitive fluidity, complexity and robustness. Table 1 shows the research matrix upon which our hypotheses, null hypotheses, research design, and findings are based.

Table 1. Four dimensions of research program.

\begin{tabular}{|c|c|c|}
\hline & $\begin{array}{c}\text { Existential } \\
\text { (Basic Research) }\end{array}$ & $\begin{array}{c}\text { Efficacy } \\
\text { (Applied Research) }\end{array}$ \\
\hline $\begin{array}{c}\text { Mind } \\
\text { (cognitive } \\
\text { complexity) }\end{array}$ & $\begin{array}{l}\text { Does DSRP Exist in Mind? } \\
\text { (i.e., Does DSRP exist as } \\
\text { universal, material, observable } \\
\text { cognitive phenomena?) }\end{array}$ & \multirow{2}{*}{$\begin{array}{c}\text { Is Metacognitive } \\
\text { Awareness of DSRP } \\
\text { Effective? } \\
\text { (i.e., Does it increase ability } \\
\text { to align cognitive complexity } \\
\text { to real-world complexity? } \\
\text { (a.k.a., parallelism) }\end{array}$} \\
\hline \multirow[t]{2}{*}{$\begin{array}{c}\text { Nature } \\
\text { (ontological } \\
\text { complexity) }\end{array}$} & $\begin{array}{c}\text { Does DSRP Exist in Nature? } \\
\text { (i.e., Does DSRP exist as } \\
\text { universal, material, observable } \\
\text { phenomena?) }\end{array}$ & \\
\hline & EMPIRIC & BASIS \\
\hline
\end{tabular}

Thus, the "fish tank studies" described herein is part of a research program that empirically tests the efficacy of DSRP in understanding Mind/Nature. Thus, this research addresses the questions: Is DSRP effective? Does metacognition of DSRP increase effectiveness in navigating cognitive complexity in order to understand system (ontological) complexity? This gets at the critically important question of "parallelism" — defined as 
the probability that our cognitive organizational rules align with nature's organizational rules-which is central to the idea of the Systems Thinking/DSRP loop ${ }^{2}$ (Figure 3).

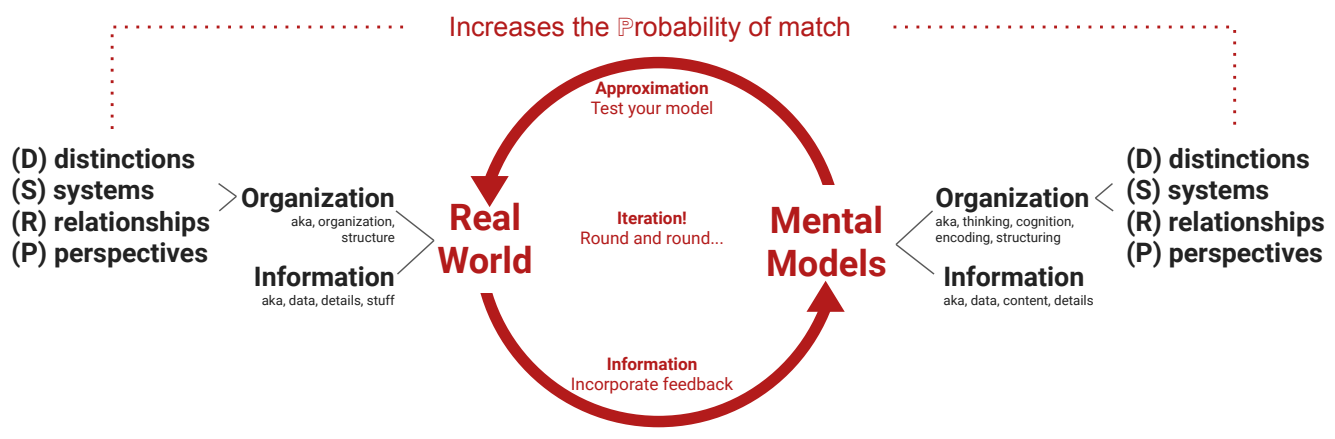

Figure 3. The ST/DSRP loop [11].

Metacognition is therefore intimately tied to systems thinking because it requires-at the very least - a recognition of mental models as existent. Beyond that, metacognition is required to build awareness and purposeful use of cognitive patterns that increase systemic thinking or cognitive complexity, rather than those structures that might cause to lessen it. Generally, research has shown that metacognitive awareness of a skill promotes and improves overall performance. As Stephen Fleming writes, "Insights into our own thoughts, or metacognition, is key to high achievement in all domains" [155]. This includes metacognitive awareness of the universal patterns of mind and nature: Distinctions, Systems, Relationships, and Perspectives (DSRP) [1-6]. Empirical studies have shown that the DSRP patterns exist universally in the mind and in nature [3]. In this study, we aim to demonstrate that through isolating the Distinction, System, Relationship, and Perspective patterns using a short ( $<1 \mathrm{~min})$ treatment, a significant effect can be made on each participant.

Metacognition, or the concept of "thinking about one's thinking", is not a new concept. Many credit John Flavell with the first use of the term metacognition in 1979 [156]. Flavell defined metacognition as, "metacognition refers to one's knowledge concerning one's own cognitive processes and products or anything related to them" (p. 232, [157]). His research focused on whether children were aware of their thinking and cognitive processes.

While Flavell coined the term, he was not the first to explore the idea of thinking about your thinking. Piaget [158] did his work in the early years of cognitive development research and wrote about "knowing the knowing and thinking the thinking" in The Psychology of Intelligence [158]. Aturk and Sahin [159] point out that the origin of thinking about your thinking could have happened much earlier.

“According to Georghiades (2004), being aware of one's cognition was already been mentioned by Plato. Likewise, Aristotle pointed out that mind used a different power above and beyond seeing and hearing and thus laid the foundations for thinking about metacognition long before (Sandí-Ureña, 2008) [159]."

Thus, in this study we form a hypothesis that making someone aware (metacognitive) of systems thinking patterns (DSRP) would increase cognitive complexity (a.k.a., a quantitative measure of the emergent property of systems thinking). Therefore, the hypothesis of this study is that metacognitive awareness of each of the isolated patterns of DSRP $(D, S, R$, and $P$ ) will have a significant effect on the cognitive complexity/systems thinking of a participant's thoughts on a simple task.

In what follows, we review the methods used for the four sub-studies (each isolating a pattern of DSRP), the results of these studies, and a discussion of these results. At the end, we summarize our findings.

\section{Methods}

Statistical analysis was performed using $\mathrm{R}$ (v3.6.3). Counts and percentages were used to summarize the distribution of categorical variables. The median and interquartile range 
were used to summarize the distribution of continuous variables. Wilcoxon signed-rank test was used to compare the distribution of raw counts, words, and characters between time points. Mixed Poisson and negative binomial regression were used to compare the distribution of counts, words, and characters between time points after adjusting for age, gender, race, and ethnicity. Hypothesis testing was performed at 5\% level of significance.

The samples used in these studies were broken into four non-duplicative groups ( $\mathrm{N}=350$ per study, $\mathrm{N}=1400$ across all four) who represented a normal distribution in the US population based on gender, education level, race, ethnicity, region (rural/urban/suburban), and age, balanced to match the census (general population).

In the study, the participants were shown a generic but detailed image of a fish tank (Figure 4).

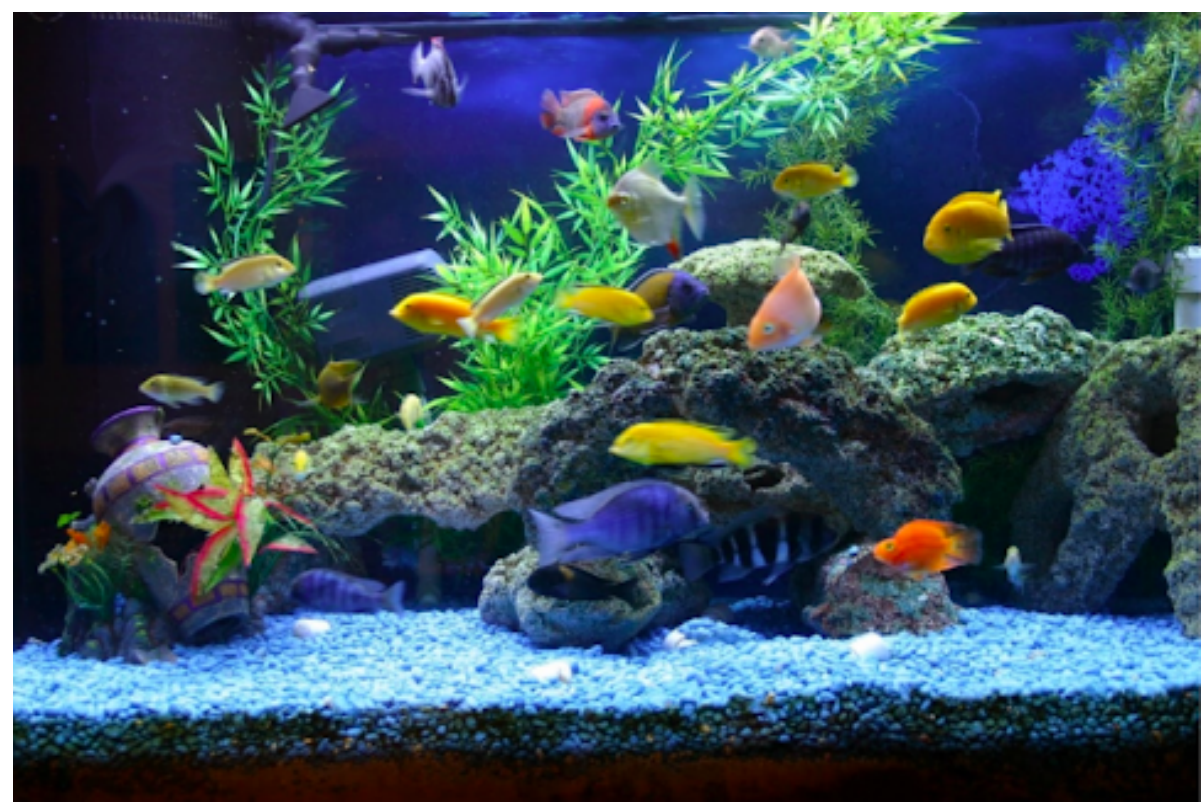

Figure 4. Fish tank image used in the experiments.

For the first part ("Pre") the participants were shown the above image on a screen and instructed to "Describe what you see in the image". After they had written their answers, depending on the pattern they were randomly assigned to, they were taken to another screen.

For the Distinction study, after the participants filled in their answers in the PreD section, they were asked to read a "Distinction-making-prime" shown in Table 2.

Table 2. Distinction treatment.

Things to consider from the identity-other Distinction Rule (D):

- Distinctions are all around us, it's how we name, identify and differentiate things, ideas, or objects from one another.

- The identity-other structure of distinctions means that any object or idea is both an identity and an other (e.g., "us" vs. "them").

- The distinctions you make can be general and/or specific (e.g., "a cup" vs. "a red porcelain cup").

- $\quad$ Often a single distinction can become many more distinctions when looks closer at its meaning (e.g., "birds" can be further distinguished to be owls, eagles, seagulls).

Then participants were shown the same fish tank image again and asked, "Describe what you see in the image when applying the Distinction Rule you just learned (text copied below the image)". This was called the Post-Distinction-making-prime (or "PostD"). 
For the Systems study, after the participants filled in their answers in the PreS section, they were asked to read a "Systems-prime" shown in Table 3.

Table 3. Systems treatment.

Things to consider from the part-whole Systems Rule (S):

- $\quad$ Systems are all around us, it's how ideas or objects are organized, grouped or nested with one another.

- $\quad$ The part-whole structure of systems means that any object or idea is both a part and a whole simultaneously (e.g., a planet is comprised of land and water and is also part of the solar system).

- In any whole system, you want to identify the relevant parts to better understand that system.

- The systems rule tells us that we can "zoom in" to see more parts and "zoom out" to see more wholes (e.g., zoom in to see the land and water parts of a planet, zoom out to see that planet as part of the solar system).

Then participants were shown the same fish tank image again and asked, "Describe what you see in the image when applying the Systems Rule you just learned (text copied below the image)". This was called the Post-Systems-prime (or "PostS").

For the Relationship study, after the participants filled in their answers in the PreR section, they were asked to read a "Relationship-prime" shown in Table 4.

Table 4. Relationships treatment.

Things to consider from the action-reaction Relationships Rule (R):

- The Relationship rule reminds us to identify and examine the relationships among all the parts of a system. In any system, you want to see not only the nodes-but also the relevant relationships among them to better understand that system.

- The action-reaction structure of relationships means that any object or idea is an action or reaction (e.g., Person A can act upon Person B or react to Person B).

- The R rule encourages not only to recognize that a relationship exists but to distinguish that relationship to better understand it (i.e., by naming it, for example the relationship between "mom" and "dad" is "marriage").

- The R rule encourages not only to recognize that a relationship exists but also to zoom into that relationship to see its constituent parts (e.g., the relationship between a farmer and consumer is a vast supply chain made up of many parts; the synaptic relationship between $=$ neurons is made up of electrochemical components).

Then participants were shown the same fish tank image again and asked, "Describe what you see in the image when applying the action-reaction Relationships Rule you just learned (text copied below the image)". This was called the Post-Relationships-prime (or "PostR").

For the Perspectives study, after the participants filled in their answers in the PreP section, they were asked to read a "Perspectives-prime" shown in Table 5. 
Table 5. Perspectives treatment.

Things to consider from the point-view Perspectives Rule (P):

- The Perspectives rule reminds us to examine systems from multiple perspectives to better understand any system.

- The point-view structure of Perspectives means that any object or idea can be a point and/or a view (e.g., A person (point) can see another person (view); or different states (point) see the parts of marriage (view) differently).

- The Perspectives Rule encourages us to take both perspectives "with eyes" (e.g., people, stakeholders, groups, countries, animals) but also non-human perspectives (e.g., economic, political, historical, structural, strengths, weaknesses, color, etc.).

- When you change the way you look at things (Perspective), the things you look at change (e.g., the Southern perspective on the Civil War includes different things than the Northern perspective on the Civil War).

- Perspectives can be used as a frame on a system that can either limit/narrow or expand/widen what you see (e.g., looking only at a system from an economicimpact perspective limits what is included while taking a holistic perspective broadens the view).

Then participants were shown the same fish tank image again and asked, "Describe what you see in the image when applying the point-view Perspectives Rule you just learned (text copied below the image)". This was called the Post-Perspectives-prime (or "PostP").

\section{Results}

We measured the average time to read the treatment which is shown in Table 6. All read-times were less than one minute and together totaled $165.61 \mathrm{~s}$ or $2.76 \mathrm{~min}$. To measure the shift in responses from PreX to PostX, a number of strategies were applied to eight different measures. We utilized counts of characters, words, and syllables of the raw data. Word clouds were used in both a qualitative and quantitative manner. Unique words were analyzed in the same way as the raw data. We also performed a textual analysis of word types and their synonyms. Lastly, we did a statistical analysis of the variance between the PreX and PostX conditions.

Table 6. Treatment read-time averages.

\begin{tabular}{ll}
\hline D-treatment & $28.11 \mathrm{~s}$ \\
S-treatment & $35.19 \mathrm{~s}$ \\
R-treatment & $51.91 \mathrm{~s}$ \\
P-treatment & $50: 40 \mathrm{~s}$ \\
\hline Total & $\mathbf{1 6 5 . 6 1 ~ \mathbf { ~ }}$ \\
\hline
\end{tabular}

The word clouds shown in this paper are quantitative data organized visually. The size of each term signifies the frequency of use of the term. Importantly, according to research by Lewis and Frank [160] word length is a valid indicator of complexity of ideas. Indeed, Lewis and Frank showed that the length of a word in characters is correlated with conceptual complexity. Lewis and Frank write:

Hypothesis 1. At the pragmatic timescale, we asked whether participants would be biased to assign a relatively long novel word to a conceptually more complex referent.

Hypothesis 2. At the language evolution timescale, we asked whether languages tended to encoded conceptually more complex meanings with longer forms.

"We found support for both hypotheses". 
They showed experimentally that "visual complexity is highly correlated with an implicit measure-reaction time-and this measure predicts the bias to assign an object a long or a short word" (p. 35 [160]). Their experimental research also shows [3] that "explicit measures of conceptual complexity in English are highly correlated with word length in English, and the corpus analysis reveals a correlation between English complexity norms and word lengths in a diverse set of languages" (p. 35 [160]).

\subsection{Distinctions}

The quantitative data for the Distinctions (D) study is shown visually in the comparison of word clouds. Below is the PreD and PostD word cloud comparisons (Table 7).

Table 7. Word cloud of response before and after distinction prompt.

PreD

The word clouds in Table 7 explicate the impact of the "Distinction-making prime". The PostD word cloud is more detailed and more descriptive than the unprimed PreD word cloud. The larger a word is, the more times it is used. In the PostD word cloud adjectives and colors are more prevalent than in the PreD word cloud. PostD also has more unique words overall. The same patterns shown visually in the word clouds are in the quantitative data as well. The PostD responses have significantly more words overall and those words are more complex. Table 8 shows the differences.

Table 8. PreD and PostD aggregate response data.

\begin{tabular}{llll}
\hline & PreD & PostD & Difference \\
\hline Number of characters (including spaces) & 17,691 & 24,308 & $+27.22 \%$ \\
Number of characters (without spaces) & 10,291 & 14,752 & $+30.24 \%$ \\
Number of words (including repeated words) & 2098 & 3071 & $+31.68 \%$ \\
Number of syllables (including repeated words) & 3246 & 4558 & $+28.78 \%$ \\
Unique words & 251 & 453 & $+44.59 \%$ \\
Number of characters (no spaces) for unique words & 1418 & 2626 & $+46.00 \%$ \\
Number of syllables for unique words & 492 & 901 & $+45.39 \%$ \\
Total unique words occurrence & 1832 & 2680 & $+31.64 \%$ \\
\hline
\end{tabular}

Table 9 shows the correlations between words for Pre and Post D. Two plots show the increased interconnectivity and complexity between words before and after the treatment for Distinction. 
Table 9. Correlation between top words used Pre and Post.

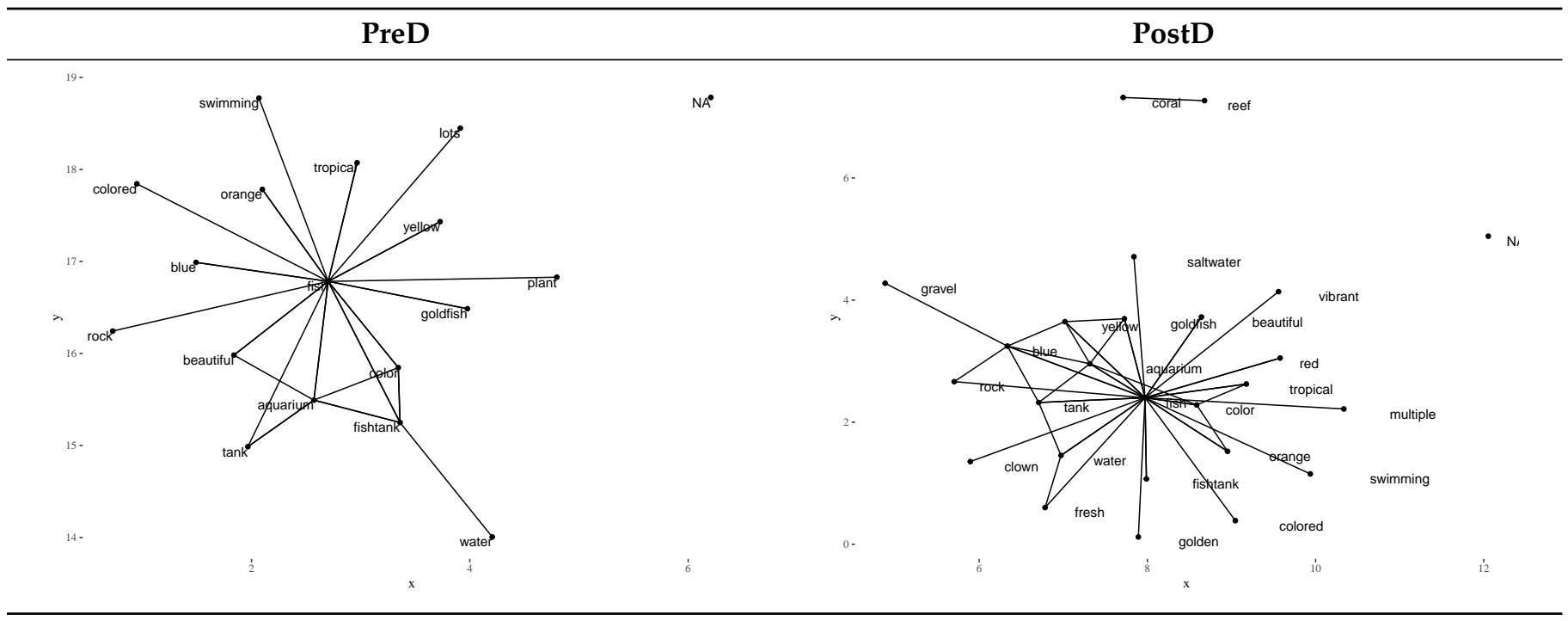

Overall, the PostD responses were more specific than the unprimed PreD responses. This is shown in the word counts and the actual words themselves. It also shows their occurrences and percentage of total occurrences. The top 10 words in the unprimed PreD section is shown in Table 10.

Table 10. Comparison of top 10 words.

\begin{tabular}{cc}
\hline PreD Top 10 Words & PostD Top 10 Words \\
\hline Fish & Fish \\
Water & Blue \\
Aquarium & Yellow \\
Fish tank & Water \\
Rock & Rock \\
Plant & Plant \\
Color & Orange \\
Blue & Aquarium \\
Tank & Color \\
Coral & Green \\
\hline
\end{tabular}

After being primed with the Distinction pattern of mind, the participants used more descriptive adjectives, in particular, colors. After a very short ( $<1 \mathrm{~min}$ read) the participants increased the specificity of their distinctions. What was once just a "fish" became a "blue fish", "yellow fish", and "orange fish". Table 11 lays out the top 40 words for the PreD and the PostD responses. 
Table 11. PreD and PostD top 40 terms used.

\begin{tabular}{|c|c|c|c|c|c|c|}
\hline \multirow[b]{2}{*}{ Rank } & \multicolumn{3}{|c|}{ PreD (Total 1848) } & \multicolumn{3}{|c|}{ PostD (Total 2695) } \\
\hline & Word & Occurs & $\%$ & Word & Occurs & $\%$ \\
\hline 1 & fish & 410 & $22.19 \%$ & fish & 542 & $20.11 \%$ \\
\hline 2 & water & 124 & $6.71 \%$ & blue & 145 & $5.38 \%$ \\
\hline 3 & aquarium & 118 & $6.39 \%$ & yellow & 115 & $4.27 \%$ \\
\hline 4 & fish tank & 92 & $4.98 \%$ & water & 114 & $4.23 \%$ \\
\hline 5 & rock & 85 & $4.60 \%$ & rock & 98 & $3.64 \%$ \\
\hline 6 & plant & 84 & $4.55 \%$ & plant & 80 & $2.97 \%$ \\
\hline 7 & color & 65 & $3.52 \%$ & orange & 74 & $2.75 \%$ \\
\hline 8 & blue & 52 & $2.81 \%$ & aquarium & 66 & $2.45 \%$ \\
\hline 9 & $\operatorname{tank}$ & 43 & $2.33 \%$ & color & 56 & $2.08 \%$ \\
\hline 10 & coral & 41 & $2.22 \%$ & green & 47 & $1.74 \%$ \\
\hline 11 & yellow & 27 & $1.46 \%$ & goldfish & 42 & $1.56 \%$ \\
\hline 12 & stone & 24 & $1.30 \%$ & tank & 40 & $1.48 \%$ \\
\hline 13 & see & 22 & $1.19 \%$ & fish tank & 40 & $1.48 \%$ \\
\hline 14 & beautiful & 20 & $1.08 \%$ & coral & 35 & $1.30 \%$ \\
\hline 15 & tropical & 17 & $0.92 \%$ & different & 31 & $1.15 \%$ \\
\hline 16 & orange & 17 & $0.92 \%$ & small & 27 & $1.00 \%$ \\
\hline 17 & gravel & 16 & $0.87 \%$ & white & 22 & $0.82 \%$ \\
\hline 18 & goldfish & 15 & $0.81 \%$ & beautiful & 20 & $0.74 \%$ \\
\hline 19 & pebbles & 15 & $0.81 \%$ & stone & 19 & $0.71 \%$ \\
\hline 20 & different & 13 & $0.70 \%$ & pebbles & 19 & $0.71 \%$ \\
\hline 21 & lots & 12 & $0.65 \%$ & gravel & 17 & $0.63 \%$ \\
\hline 22 & grass & 11 & $0.60 \%$ & swimming & 17 & $0.63 \%$ \\
\hline 23 & swimming & 11 & $0.60 \%$ & with & 17 & $0.63 \%$ \\
\hline 24 & some & 11 & $0.60 \%$ & see & 17 & $0.63 \%$ \\
\hline 25 & seaweed & 10 & $0.54 \%$ & many & 16 & $0.59 \%$ \\
\hline 26 & decorations & 10 & $0.54 \%$ & vase & 16 & $0.59 \%$ \\
\hline 27 & very & 9 & $0.49 \%$ & clear & 15 & $0.56 \%$ \\
\hline 28 & filter & 9 & $0.49 \%$ & that & 13 & $0.48 \%$ \\
\hline 29 & tree & 8 & $0.43 \%$ & broken & 12 & $0.45 \%$ \\
\hline 30 & green & 8 & $0.43 \%$ & very & 12 & $0.45 \%$ \\
\hline 31 & clean & 8 & $0.43 \%$ & red & 12 & $0.45 \%$ \\
\hline 32 & fake & 8 & $0.43 \%$ & tropical & 11 & $0.41 \%$ \\
\hline 33 & pipe & 7 & $0.38 \%$ & seaweed & 11 & $0.41 \%$ \\
\hline 34 & many & 7 & $0.38 \%$ & vs & 10 & $0.37 \%$ \\
\hline 35 & vase & 7 & $0.38 \%$ & grey & 10 & $0.37 \%$ \\
\hline 36 & nice & 7 & $0.38 \%$ & colored & 9 & $0.33 \%$ \\
\hline 37 & sand & 7 & $0.38 \%$ & light & 9 & $0.33 \%$ \\
\hline 38 & life & 6 & $0.32 \%$ & large & 9 & $0.33 \%$ \\
\hline 39 & like & 6 & $0.32 \%$ & multiple & 8 & $0.30 \%$ \\
\hline 40 & colored & 6 & $0.32 \%$ & pipe & 8 & $0.30 \%$ \\
\hline
\end{tabular}

Results in Tables 12 and 13 show that the distribution of number of concepts (i.e., the number of individual entries the subject made, "raw data") was not significantly different before and after treatment ( $p=0.062$ using Wilcoxon signed-rank test). Data $(\mathrm{N}=383$ ) were summarized using median (IQR). Statistical analysis was performed using Wilcoxon-signed rank test. However, the median number of words used after treatment (Mdn =6, IQR 3-10) was significantly higher than the median number of words used before treatment $(\mathrm{Mdn}=4$, IQR 3-7, $p<0.001^{* * *}$ ). Similarly, the median number of characters used after treatment $(\mathrm{M}=29$, IQR 14-53) was significantly higher than the median number of characters used before treatment $\left(\mathrm{Mdn}=12\right.$, IQR 13-36, $\left.p<0.001^{* * *}\right)$. 
Table 12. Distribution of words and characters (vertical lines represent median) for Distinctions (D).

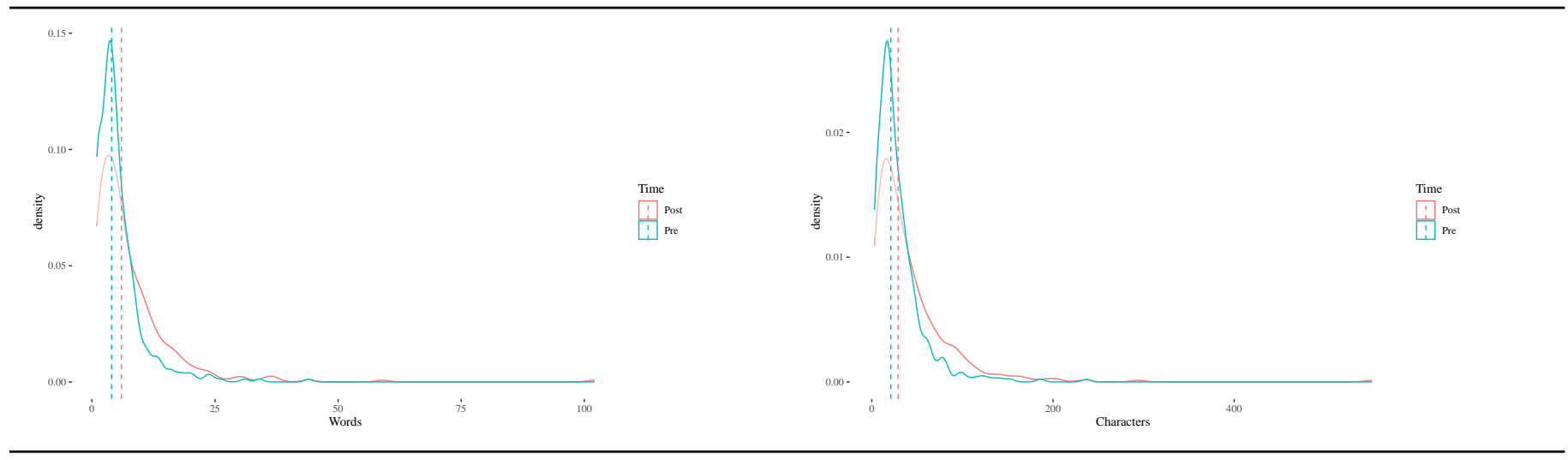

Table 13. Comparison of raw counts, words, and characters before and after D-treatment.

\begin{tabular}{llll}
\hline & Pre & Post & P.overall \\
\hline No. concepts & $3.00[1.00 ; 4.00]$ & $3.00[1.00 ; 4.00]$ & 0.062 \\
No. words & $4.00[3.00 ; 7.00]$ & $6.00[3.00 ; 10.0]$ & $<0.001$ \\
No. characters & $21.0[13.0 ; 36.0]$ & $29.0[14.0 ; 53.0]$ & $<0.001$ \\
\hline
\end{tabular}

Figure 5 shows the difference in the use of any given word ( $x$-axis) between Post and Pre. Data were filtered to only include words mentioned more than five times, such that positive numbers indicate higher word counts post treatment. A positive number indicates that the word was used more post treatment while a negative indicates the less post treatment. For example, the word blue was used 93 more times post-treatment indicating more refined distinction making.

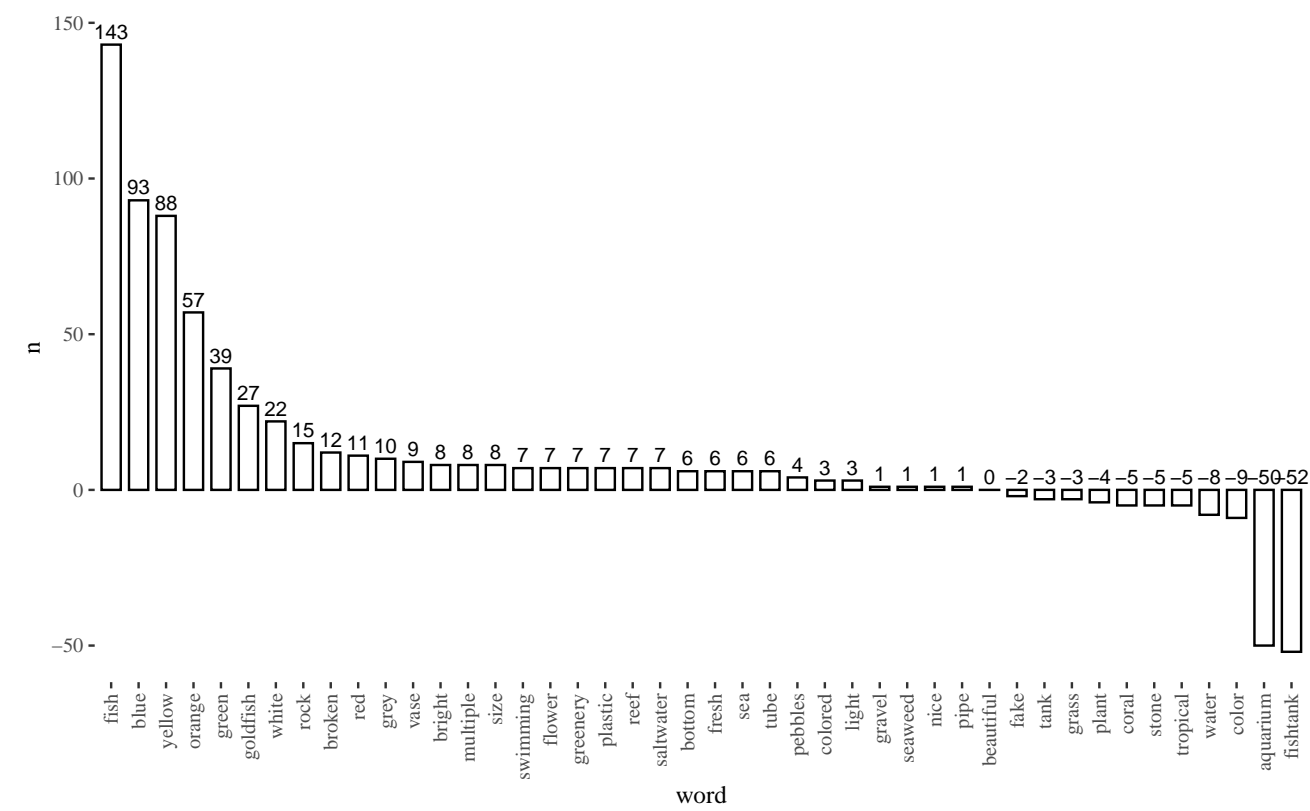

Figure 5. Difference in word count before and after D treatment.

Results in Table 14 show that the expected average count was not significantly different before and after treatment (IRR $=1.05, p=0.201)$. However, the expected number of words was higher by $43 \%$ post-treatment than before treatment (IRR $\left.=1.43, p<0.001^{* * *}\right)$. Similarly, the expected average number of characters was higher by $41 \%$ post-treatment than pretreatment $\left(\operatorname{IRR}=1.41, p<0.001^{* * *}\right)$. Education and Age were not statistically significant 
factors in pre-post differences, indicating universality. Male gender was associated with lower expected number of words (IRR $=0.67, p<0.001^{* * *}$ ) and characters $($ IRR $=0.69$, $\left.p<0.001^{* * *}\right)$.

Table 14. D mixed generalized linear regression.

\begin{tabular}{|c|c|c|c|c|c|c|}
\hline Predictors & $\begin{array}{l}\text { No. Concepts } \\
\text { Incidence Rate Ratios }\end{array}$ & $p$ & $\begin{array}{l}\text { No. Words } \\
\text { Incidence Rate Ratios }\end{array}$ & $p$ & $\begin{array}{l}\text { No. Characters } \\
\text { Incidence Rate Ratios }\end{array}$ & $p$ \\
\hline (Intercept) & $2.69(1.91-3.77)$ & $<0.001$ & $3.07(2.01-4.69)$ & $<0.001$ & $17.31(11.43-26.21)$ & $<0.001$ \\
\hline Time (Post vs. Pre) & $1.05(0.97-1.14)$ & 0.201 & $1.43(1.34-1.53)$ & $<0.001$ & $1.41(1.31-1.51)$ & $<0.001$ \\
\hline Age (1 level increase) & $0.98(0.96-1.01)$ & 0.175 & $1.00(0.97-1.04)$ & 0.878 & $1.01(0.97-1.04)$ & 0.749 \\
\hline Education (1 level increase) & $0.00(0.96-1.04)$ & 0.913 & $1.00(0.95-1.05)$ & 0.972 & $1.00(0.95-1.04)$ & 0.907 \\
\hline Ethnicity (Not Latino and/or Hispanic) & $0.97(0.81-1.16)$ & 0.750 & $1.04(0.83-1.30)$ & 0.734 & $1.03(0.83-1.28)$ & 0.803 \\
\hline Gender (Male) & $0.89(0.79-1.00)$ & 0.053 & $0.67(0.58-0.78)$ & $<0.001$ & $0.69(0.60-0.80)$ & $<0.001$ \\
\hline Marginal $R^{2} /$ Conditional $R^{2}$ & $0.013 / 0.365$ & & $0.107 / 0.664$ & & $0.095 / 0.621$ & \\
\hline
\end{tabular}

\subsection{Systems}

The quantitative data for the Systems (S) study is shown visually in the comparison of word clouds. Below is the PreS and PostS word cloud comparisons (Table 15).

Table 15. Word cloud of response before and after system prompt.

Pres

The word clouds in Table 15 demonstrate the impact of the Systems prime. The PostS word cloud is more detailed and more descriptive than the unprimed PreS word cloud. The larger a word is, the more times it is used. Certain terminologies-such as ecosystem, system, whole, zoom, and part-are much more prevalent in the PostS and nonexistent in PreS. PostS also has more unique words overall. The same patterns shown visually in the word clouds are in the quantitative data as well. The responses in the PostS have significantly more words overall and those words are more complex. Table 16 shows the quantitative data analysis.

Overall, the PostS responses were more "systemic" than the unprimed PreS responses. This is shown in the words themselves including: system (38), part (23), whole (16), contain (12), zoom (12), group (8), habitat (6), together (6), community (4), environment (4), organisms (4), organized (2), entirety (2), biosystem (1), gestalt (1), microscopic (1), neighborhood (1), population (1). These terms make up $7.44 \%$ of the total words in the PostS data.

After being primed with the systems pattern of mind, the participants used more systemic language. They were more focused on part-whole aspects of the fish tank image. After a very short ( $<1 \mathrm{~min}$ read) the participants increased their focus on systems. Table 17 lays out the top 40 words for the PreS and the PostS responses. It also shows their occurrences and percentage of total occurrences. 
Table 16. PreS and PostS aggregate response data.

\begin{tabular}{llll}
\hline & PreS & PostS & Difference \\
\hline Number of characters (including spaces) & 17,061 & 19,367 & $+11.91 \%$ \\
Number of characters (without spaces) & 10,318 & 11,350 & $+9.09 \%$ \\
Number of words (including repeated words) & 2092 & 2410 & $+13.20 \%$ \\
Number of syllables (including repeated words) & 3207 & 3654 & $+12.23 \%$ \\
Unique words & 243 & 416 & $+41.59 \%$ \\
Number of characters (no spaces) for unique words & 1226 & 2414 & $+49.21 \%$ \\
Number of syllables for unique words & 472 & 828 & $+43.00 \%$ \\
Total unique words occurrence & 1911 & 2009 & $+4.88 \%$ \\
\hline
\end{tabular}

Table 17. PreS and PostS top 40 terms used.

\begin{tabular}{|c|c|c|c|c|c|c|}
\hline \multirow[b]{2}{*}{ Rank } & \multicolumn{3}{|c|}{ PreS (Total 1911) } & \multicolumn{3}{|c|}{ PostS (Total 2009) } \\
\hline & Word & Occurs & $\%$ & Word & Occurs & $\%$ \\
\hline 1 & fish & 416 & $19.78 \%$ & fish & 305 & $12.66 \%$ \\
\hline 2 & water & 136 & $6.47 \%$ & water & 145 & $6.02 \%$ \\
\hline 3 & aquarium & 131 & $6.23 \%$ & aquarium & 92 & $3.82 \%$ \\
\hline 4 & rock & 94 & $4.47 \%$ & plant & 92 & $3.82 \%$ \\
\hline 5 & plant & 86 & $4.09 \%$ & rock & 68 & $2.82 \%$ \\
\hline 6 & fish tank & 77 & $3.66 \%$ & fish tank & 56 & $2.32 \%$ \\
\hline 7 & blue & 61 & $2.90 \%$ & tank & 44 & $1.83 \%$ \\
\hline 8 & coral & 57 & $2.71 \%$ & and & 40 & $1.66 \%$ \\
\hline 9 & color & 41 & $1.95 \%$ & blue & 39 & $1.62 \%$ \\
\hline 10 & $\operatorname{tank}$ & 39 & $1.85 \%$ & system & 38 & $1.58 \%$ \\
\hline 11 & yellow & 35 & $1.66 \%$ & color & 27 & $1.12 \%$ \\
\hline 12 & gravel & 31 & $1.47 \%$ & ecosystem & 27 & $1.12 \%$ \\
\hline 13 & orange & 31 & $1.47 \%$ & coral & 24 & $1.00 \%$ \\
\hline 14 & and & 28 & $1.33 \%$ & gravel & 24 & $1.00 \%$ \\
\hline 15 & stone & 22 & $1.05 \%$ & part & 23 & $0.95 \%$ \\
\hline 16 & with & 22 & $1.05 \%$ & see & 19 & $0.79 \%$ \\
\hline 17 & seaweed & 17 & $0.81 \%$ & stone & 18 & $0.75 \%$ \\
\hline 18 & green & 16 & $0.76 \%$ & with & 18 & $0.75 \%$ \\
\hline 19 & swimming & 16 & $0.76 \%$ & swimming & 16 & $0.66 \%$ \\
\hline 20 & pebbles & 15 & $0.71 \%$ & vase & 16 & $0.66 \%$ \\
\hline 21 & tropical & 15 & $0.71 \%$ & whole & 16 & $0.66 \%$ \\
\hline 22 & vase & 15 & $0.71 \%$ & yellow & 15 & $0.62 \%$ \\
\hline 23 & decorations & 14 & $0.67 \%$ & pebbles & 13 & $0.54 \%$ \\
\hline 24 & white & 14 & $0.67 \%$ & sea & 13 & $0.54 \%$ \\
\hline 25 & broken & 13 & $0.62 \%$ & contain & 12 & $0.50 \%$ \\
\hline 26 & filter & 13 & $0.62 \%$ & green & 12 & $0.50 \%$ \\
\hline 27 & reef & 12 & $0.57 \%$ & orange & 12 & $0.50 \%$ \\
\hline 28 & see & 11 & $0.52 \%$ & this & 12 & $0.50 \%$ \\
\hline 29 & different & 10 & $0.48 \%$ & zoom & 12 & $0.50 \%$ \\
\hline 30 & light & 10 & $0.48 \%$ & decorations & 11 & $0.46 \%$ \\
\hline 31 & saltwater & 10 & $0.48 \%$ & school & 11 & $0.46 \%$ \\
\hline 32 & tree & 10 & $0.48 \%$ & different & 10 & $0.41 \%$ \\
\hline 33 & lots & 9 & $0.43 \%$ & on & 10 & $0.41 \%$ \\
\hline 34 & on & 9 & $0.43 \%$ & bubbles & 9 & $0.37 \%$ \\
\hline 35 & sand & 9 & $0.43 \%$ & light & 9 & $0.37 \%$ \\
\hline 36 & sea & 9 & $0.43 \%$ & living & 9 & $0.37 \%$ \\
\hline 37 & bottom & 8 & $0.38 \%$ & also & 8 & $0.33 \%$ \\
\hline 38 & many & 8 & $0.38 \%$ & glass & 8 & $0.33 \%$ \\
\hline 39 & small & 8 & $0.38 \%$ & group & 8 & $0.33 \%$ \\
\hline 40 & grass & 7 & $0.33 \%$ & life & 8 & $0.33 \%$ \\
\hline
\end{tabular}

Results in Figure 6 and Table 18 show that the distribution of concepts was significantly different before and after treatment $\left(p=<0.001^{* * *}\right.$ using Wilcoxon signed-rank test). Data was summarized using median (IQR). Statistical analysis was performed using 
Wilcoxon-signed rank test. The distribution of the number of words and characters was not significantly different before and after treatment.

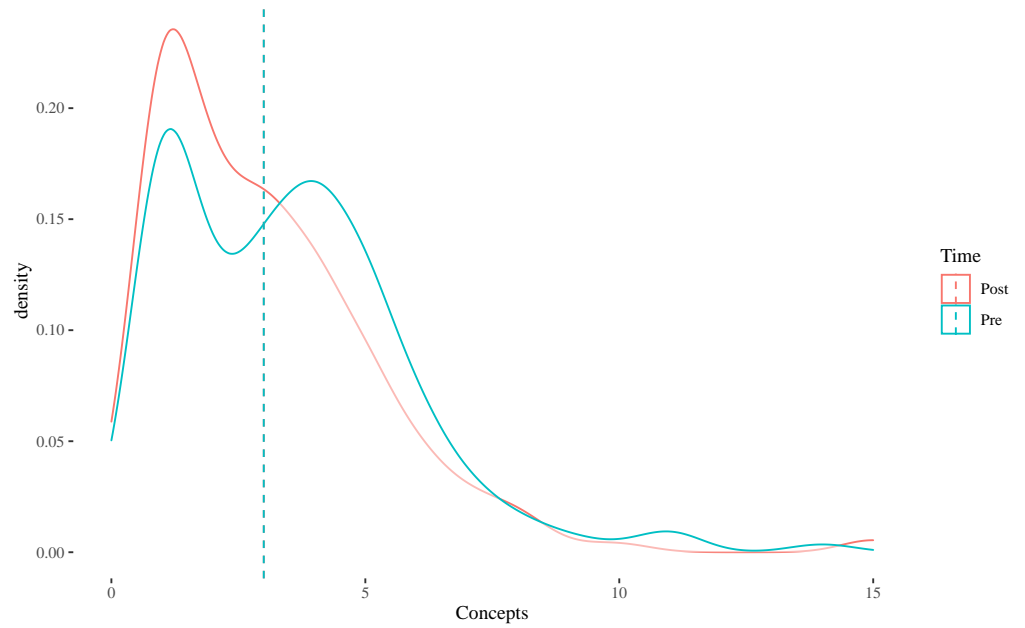

Figure 6. Distribution of Systems (S) concepts (vertical lines represent median).

Table 18. S comparison of raw counts, words, and characters before and after treatment.

\begin{tabular}{llll}
\hline & Pre & Post & P.overall \\
\hline No. concepts & $3.00[1.00 ; 5.00]$ & $3.00[1.00 ; 4.00]$ & $<0.001$ \\
No. words & $4.00[3.00 ; 7.00]$ & $4.00[2.00 ; 7.00]$ & 0.13 \\
No. characters & $23.0[14.0 ; 35.8]$ & $22.0[13.0 ; 39.0]$ & 0.13 \\
\hline
\end{tabular}

Figure 7 shows the difference in the use of any given word ( $x$-axis) between Post and Pre. Data were filtered to only include words mentioned more than five times, such that positive numbers indicate higher word counts post treatment. A positive number indicates that the word was used more post treatment while a negative indicates the less post treatment. For example, the word system was used 34 more times and the word ecosystem was used 23 more times post-treatment indicating that subjects identified systemic concepts with part-whole structure.

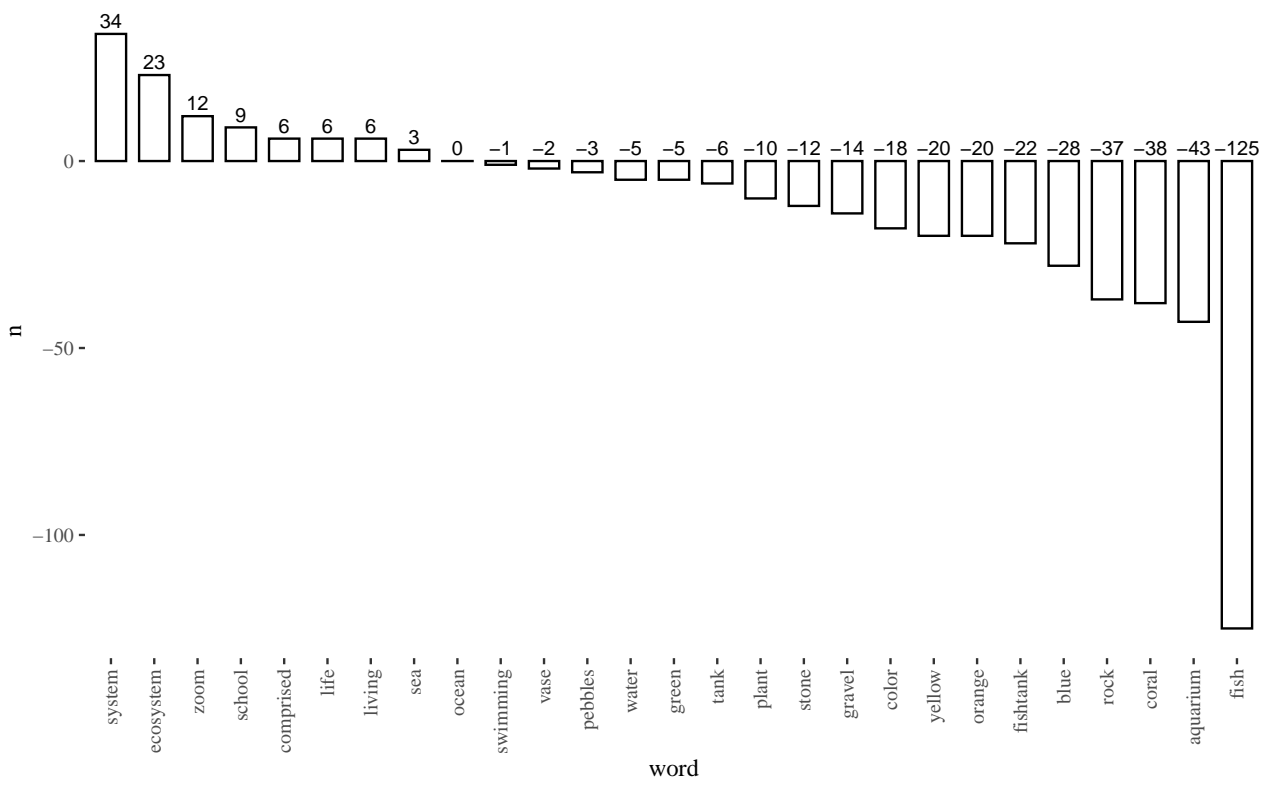

Figure 7. Difference in word count before and after $S$ treatment. 
Table 19. S mixed generalized linear regression.

\begin{tabular}{|c|c|c|c|c|c|c|}
\hline Predictors & $\begin{array}{l}\text { No. Concepts } \\
\text { Incidence Rate Ratios }\end{array}$ & $p$ & $\begin{array}{l}\text { No. Words } \\
\text { Incidence Rate Ratios }\end{array}$ & $p$ & $\begin{array}{l}\text { No. Characters } \\
\text { Incidence Rate Ratios }\end{array}$ & $p$ \\
\hline Time (Post vs. Pre) & $0.87(0.81-0.95)$ & $<0.001$ & $1.12(1.02-1.22)$ & 0.015 & $1.08(0.99-1.17)$ & 0.091 \\
\hline Age (1 level increase) & $1.02(0.99-1.04)$ & 0.259 & $1.06(1.03-1.10)$ & $<0.001$ & $1.06(1.03-1.10)$ & $<0.001$ \\
\hline Education (1 level increase) & $0.99(0.95-1.03)$ & 0.579 & $1.00(0.96-1.05)$ & 0.847 & $1.01(0.97-1.06)$ & 0.622 \\
\hline Ethnicity (Not Latino and/or Hispanic) & $1.06(0.88-1.28)$ & 0.538 & $0.99(0.79-1.25)$ & 0.959 & $0.98(0.79-1.22)$ & 0.847 \\
\hline Gender (Male) & $0.93(0.82-1.05)$ & 0.253 & $0.85(0.73-0.99)$ & 0.039 & $0.85(0.73-0.98)$ & 0.027 \\
\hline Marginal $R^{2} /$ Conditional $R^{2}$ & $0.017 / 0.399$ & & $0.039 / 0.483$ & & $0.040 / 0.470$ & \\
\hline
\end{tabular}

Data were analyzed (19) using Poisson regression for concepts and using negative binomial regression for words and characters. Results showed that the expected number of concepts was lower by $13 \%$ after treatment than before treatment (IRR $=0.87, p<0.001$ $* * *)$. However, the expected number of words was higher by $12 \%$ post-treatment than before treatment (IRR $=1.12, p=0.015^{* *}$ ). The expected number of characters was higher by $8 \%$ post-treatment than pre-treatment (IRR $=1.06, p=0.091$ ) although the result was statistically significant at the 0.1 level only. Male gender and younger age were associated with an overall lower number of words and characters. Ethnicity and education were not significantly different before and after intervention.

\subsection{Relationships}

The data for the Relationships (R) study is applied visually in the comparison of word clouds. Below is the PreR and PostR word cloud comparisons (Table 20).

Table 20. Word cloud of response before and after relationships prompt.

\begin{tabular}{|c|c|}
\hline PreR & PostR \\
\hline 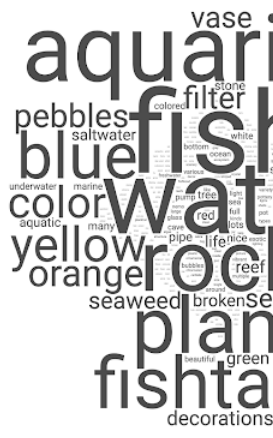 & 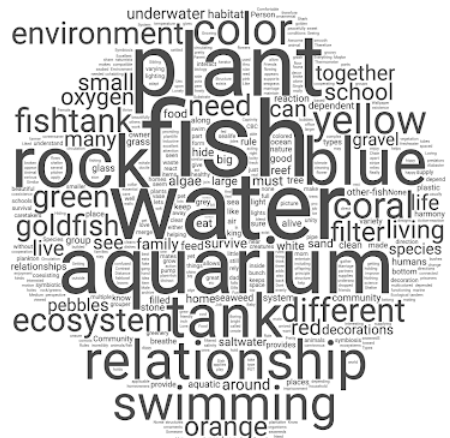 \\
\hline
\end{tabular}

The above word clouds demonstrate the impact of the "Relationships prime". The Post $\mathrm{R}$ word cloud is more detailed and more descriptive than the unprimed PreR word cloud. The larger a word is, the more times it is used. Smaller words indicate more overall detail and more words used among each participant. Relational words-like relationship, and, to, between - are shown in the PostR and nonexistent in the PreR data. PostR also has more unique words overall. The same patterns shown visually in the word clouds are in the quantitative data as well. The responses in the PostR have significantly more words overall and those words are more relational. Table 21 shows the quantitative data analysis.

Overall, the PostR responses were more interrelational than the unprimed PreR responses. This is shown in the actual words used by the participants. This includes "connector" words such as: and (78), in (67), of (61), to (61), relationship (41), are (32), for (24), with (20), different (16), between (16). Relational words were 2.96 times more common, -ing words were 1.40 times more common, and verbs were 6.38 times more common in the PostR data than in PreR. 
Table 21. PreR and PostR aggregate response data.

\begin{tabular}{llll}
\hline & PreR & PostR & Difference \\
\hline Number of characters (including spaces) & 18,443 & 21,965 & $+16.03 \%$ \\
Number of characters (without spaces) & 11,271 & 13,132 & $+14.17 \%$ \\
Number of words (including repeated words) & 2248 & 2814 & $+20.11 \%$ \\
Number of syllables (including repeated words) & 3532 & 2814 & $+20.11 \%$ \\
Unique words & 279 & 466 & $+40.13 \%$ \\
Number of characters (no spaces) for unique words & 1578 & 2684 & $+41.21 \%$ \\
Number of syllables for unique words & 537 & 926 & $+42.01 \%$ \\
Total unique words occurrence & 2138 & 2553 & $+16.26 \%$ \\
\hline
\end{tabular}

Table 22 lays out the top 40 words for the PreR and the PostR responses. It also shows their occurrences and percentage of total occurrences. The PostR condition includes many more connector words than the PreR.

Table 22. PreR and PostR top 40 terms used.

\begin{tabular}{|c|c|c|c|c|c|c|}
\hline \multirow[b]{2}{*}{ Rank } & \multicolumn{3}{|c|}{ PreR (Total 2138) } & \multicolumn{3}{|c|}{ PostR (Total 2553) } \\
\hline & Word & Occurs & $\%$ & Word & Occurs & $\%$ \\
\hline 1 & fish & 440 & $19.78 \%$ & fish & 404 & $14.36 \%$ \\
\hline 2 & water & 151 & $6.79 \%$ & water & 154 & $5.47 \%$ \\
\hline 3 & aquarium & 127 & $5.71 \%$ & and & 78 & $2.77 \%$ \\
\hline 4 & rock & 116 & $5.21 \%$ & in & 67 & $2.38 \%$ \\
\hline 5 & plant & 99 & $4.45 \%$ & plant & 62 & $2.38 \%$ \\
\hline 6 & blue & 65 & $2.92 \%$ & of & 61 & $2.17 \%$ \\
\hline 7 & fish tank & 64 & $2.88 \%$ & to & 61 & $2.17 \%$ \\
\hline 8 & coral & 55 & $2.47 \%$ & aquarium & 56 & $1.99 \%$ \\
\hline 9 & color & 43 & $1.93 \%$ & rock & 49 & $1.74 \%$ \\
\hline 10 & $\operatorname{tank}$ & 41 & $1.80 \%$ & blue & 41 & $1.46 \%$ \\
\hline 11 & yellow & 40 & $1.80 \%$ & relationship & 41 & $1.46 \%$ \\
\hline 12 & gravel & 35 & $1.57 \%$ & $\operatorname{tank}$ & 40 & $1.42 \%$ \\
\hline 13 & orange & 33 & $1.48 \%$ & are & 32 & $1.14 \%$ \\
\hline 14 & of & 31 & $1.39 \%$ & is & 30 & $1.07 \%$ \\
\hline 15 & in & 24 & $1.08 \%$ & swimming & 28 & $1.00 \%$ \\
\hline 16 & and & 20 & $0.90 \%$ & color & 26 & $0.92 \%$ \\
\hline 17 & filter & 20 & $0.90 \%$ & for & 24 & $0.85 \%$ \\
\hline 18 & pebbles & 20 & $0.90 \%$ & yellow & 23 & $0.82 \%$ \\
\hline 19 & vase & 19 & $0.85 \%$ & coral & 21 & $0.75 \%$ \\
\hline 20 & see & 17 & $0.76 \%$ & with & 20 & $0.71 \%$ \\
\hline 21 & tropical & 17 & $0.76 \%$ & good & 19 & $0.68 \%$ \\
\hline 22 & goldfish & 16 & $0.72 \%$ & other & 19 & $0.68 \%$ \\
\hline 23 & seaweed & 16 & $0.72 \%$ & ecosystem & 17 & $0.60 \%$ \\
\hline 24 & with & 16 & $0.72 \%$ & different & 16 & $0.57 \%$ \\
\hline 25 & decorations & 13 & $0.58 \%$ & environment & 16 & $0.57 \%$ \\
\hline 26 & swimming & 13 & $0.58 \%$ & fish tank & 16 & $0.57 \%$ \\
\hline 27 & different & 12 & $0.54 \%$ & that & 16 & $0.57 \%$ \\
\hline 28 & reef & 12 & $0.54 \%$ & between & 15 & $0.53 \%$ \\
\hline 29 & broken & 11 & $0.49 \%$ & green & 15 & $0.53 \%$ \\
\hline 30 & green & 11 & $0.49 \%$ & need & 15 & $0.53 \%$ \\
\hline 31 & fake & 10 & $0.45 \%$ & be & 14 & $0.50 \%$ \\
\hline 32 & life & 10 & $0.45 \%$ & filter & 14 & $0.50 \%$ \\
\hline 33 & saltwater & 10 & $0.45 \%$ & goldfish & 14 & $0.50 \%$ \\
\hline 34 & decoration & 9 & $0.40 \%$ & on & 14 & $0.50 \%$ \\
\hline 35 & is & 9 & $0.40 \%$ & each & 13 & $0.46 \%$ \\
\hline 36 & small & 9 & $0.40 \%$ & orange & 13 & $0.46 \%$ \\
\hline 37 & aquatic & 8 & $0.36 \%$ & living & 12 & $0.43 \%$ \\
\hline 38 & are & 8 & $0.36 \%$ & can & 11 & $0.39 \%$ \\
\hline 39 & pipe & 8 & $0.36 \%$ & oxygen & 11 & $0.39 \%$ \\
\hline 40 & red & 8 & $0.36 \%$ & school & 11 & $0.39 \%$ \\
\hline
\end{tabular}


Data $(\mathrm{N}=382)$ were summarized using median (IQR). Statistical analysis was performed using Wilcoxon-signed rank test. Results in in Figures 8-10 and Table 23 show that the distribution of concepts was significantly different before and after treatment $\left(p=<0.001^{* * *}\right.$ using Wilcoxon signed-rank test) with a lower average number of concepts observed after treatment. The distribution of the number of words used after treatment ( $M=4$, IQR 2-9) was significantly different from that observed before treatment $(M=4$, IQR 3-7, $p=0.003 *$ ). The distribution of the number of characters used after treatment $(\mathrm{M}=23, \mathrm{IQR} 10-51)$ was significantly higher than the median number of words used before treatment $\left(\mathrm{M}=23\right.$, IQR $\left.13-38, p=0.015^{*}\right)$.

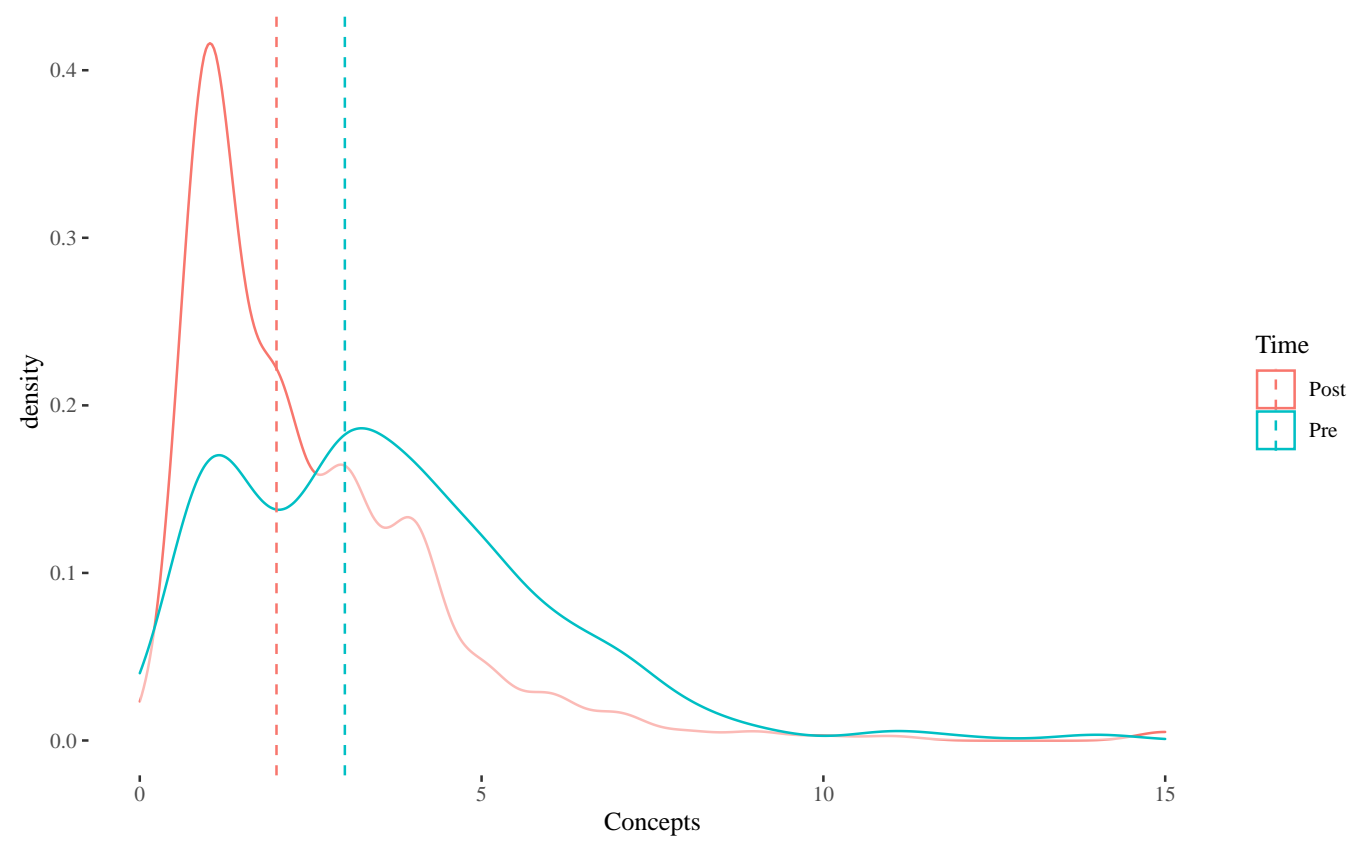

Figure 8. Distribution of concepts for PreR and PostR (vertical lines represent median).

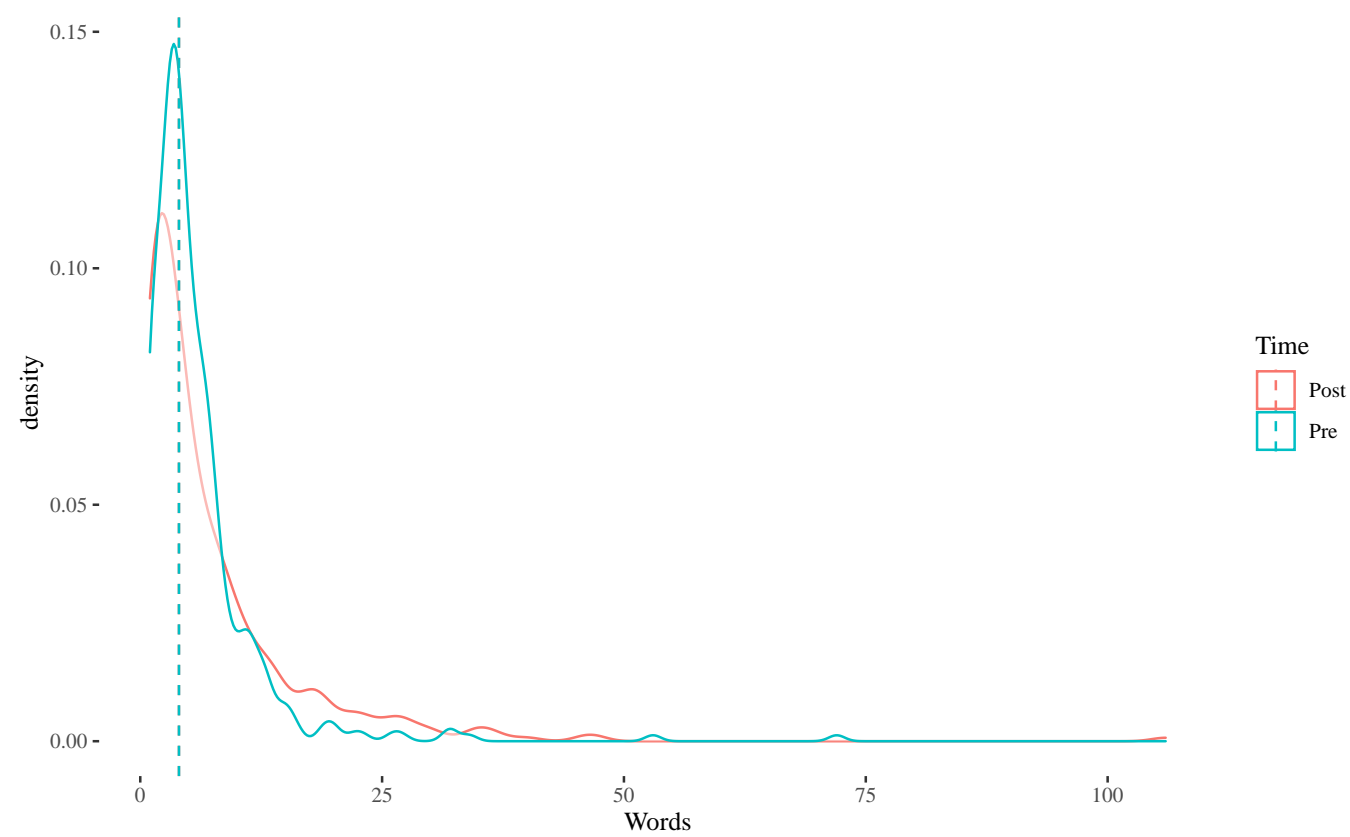

Figure 9. Distribution of words for PreR and PostR (vertical lines represent median). 


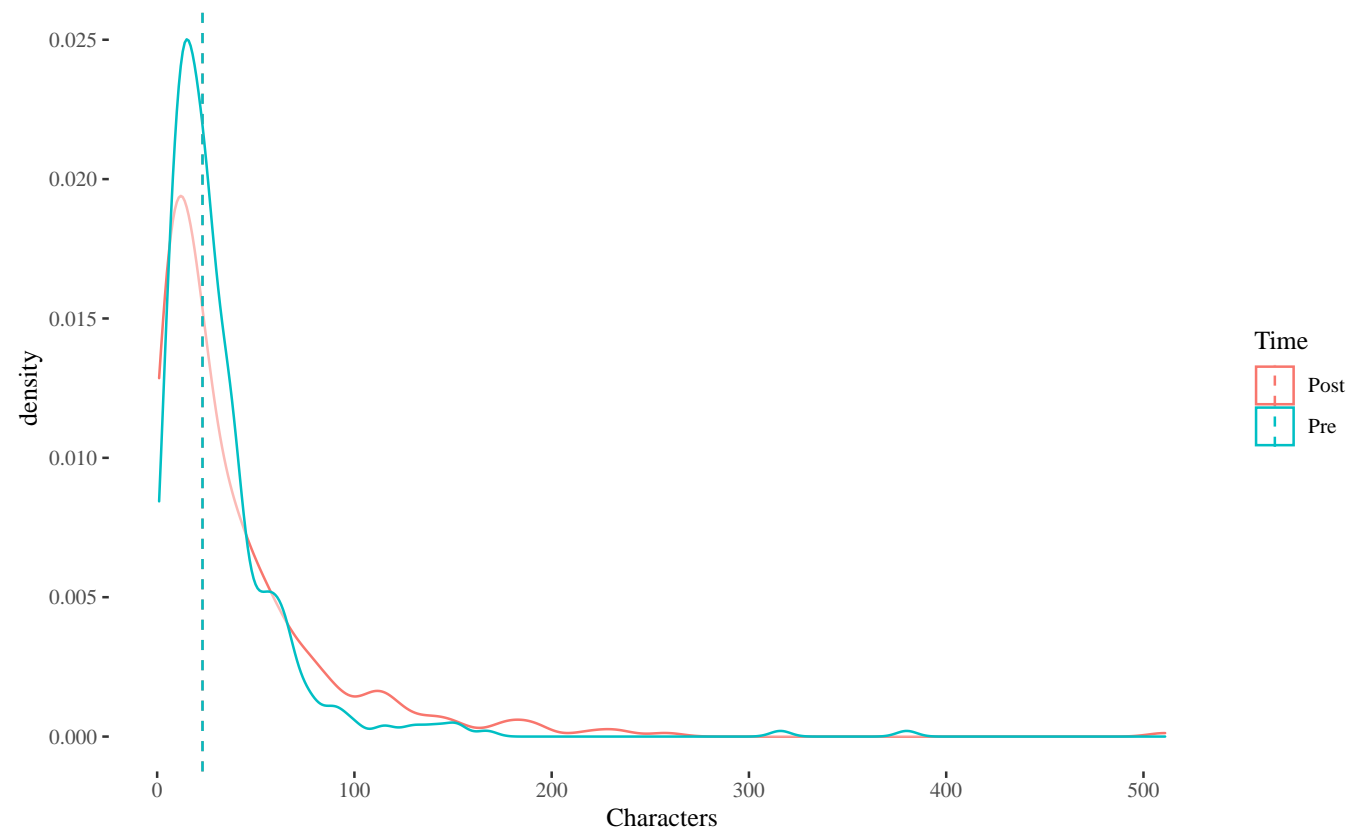

Figure 10. Distribution of characters for PreR and PostR (vertical lines represent median).

Table 23. R comparison of raw counts, words, and characters before and after treatment.

\begin{tabular}{llll}
\hline & Pre & Post & P.overall \\
\hline No. concepts & $3.00[2.00 ; 5.00]$ & $2.00[1.00 ; 3.00]$ & $<\mathbf{0 . 0 0 1}$ \\
No. words & $4.00[3.00 ; 7.00]$ & $4.00[2.00 ; 9.00]$ & $\mathbf{0 . 0 0 3}$ \\
No. characters & $23.0[13.0 ; 38.0]$ & $23.0[10.2 ; 50.8]$ & $\mathbf{0 . 0 1 5}$ \\
\hline
\end{tabular}

Figure 11 shows the difference in the use of any given word ( $x$-axis) between Post and Pre. Data were filtered to only include words mentioned more than five times, such that positive numbers indicate higher word counts post treatment. A positive number indicates that the word was used more post treatment while a negative indicates the less post treatment. For example, the word relationship was used 29 more times and the word swimming was used 15 more times post-treatment indicating that subjects identified relational concepts more often.

Data were analyzed (Table 24) using Poisson regression for concepts and using negative binomial regression for words and characters. Results showed that the expected number of concepts was lower by $30 \%$ after treatment than before treatment (IRR $=0.69$, $\left.p<0.001^{* * *}\right)$. However, the expected number of words was higher by $21 \%$ post-treatment than before treatment $\left(\operatorname{IRR}=1.21, p<0.001^{* * *}\right)$. Similarly, the expected number of characters was higher by $14 \%$ post-treatment than pre-treatment (IRR $=1.14, p=0.004{ }^{* *}$ ). Male gender, and younger age were associated with an overall lower number of words and characters. Ethnicity and education were not significantly different before and after intervention.

Table 24. R mixed generalized linear regression.

\begin{tabular}{|c|c|c|c|c|c|c|}
\hline & No. Concepts & & No. Words & & No. Characters & \\
\hline Predictors & Incidence Rate Ratios & $p$ & Incidence Rate Ratios & $p$ & Incidence Rate Ratios & $p$ \\
\hline Time (Post vs. Pre) & $0.69(0.63-0.75)$ & $<0.001$ & $1.21(1.11-1.32)$ & $<0.001$ & $1.14(1.04-1.24)$ & 0.004 \\
\hline Age (1 level increase) & $1.00(0.97-1.03)$ & 0.948 & $1.03(1.00-1.07)$ & 0.050 & $1.04(1.00-1.07)$ & 0.031 \\
\hline Education (1 level increase) & $0.99(0.95-1.02)$ & 0.511 & $1.01(0.96-1.06)$ & 0.668 & $1.01(0.96-1.06)$ & 0.752 \\
\hline Ethnicity (Not Latino and/or Hispanic) & $1.00(0.85-1.17)$ & 0.962 & $1.06(0.85-1.32)$ & 0.597 & $1.04(0.84-1.28)$ & 0.728 \\
\hline Gender (Male) & $0.93(0.83-1.05)$ & 0.251 & $0.75(0.65-0.88)$ & $<0.001$ & $0.77(0.66-0.89)$ & $<0.001$ \\
\hline Marginal R2 / Conditional R2 & $0.076 / 0.370$ & & $0.051 / 0.517$ & & $0.041 / 0.481$ & \\
\hline
\end{tabular}




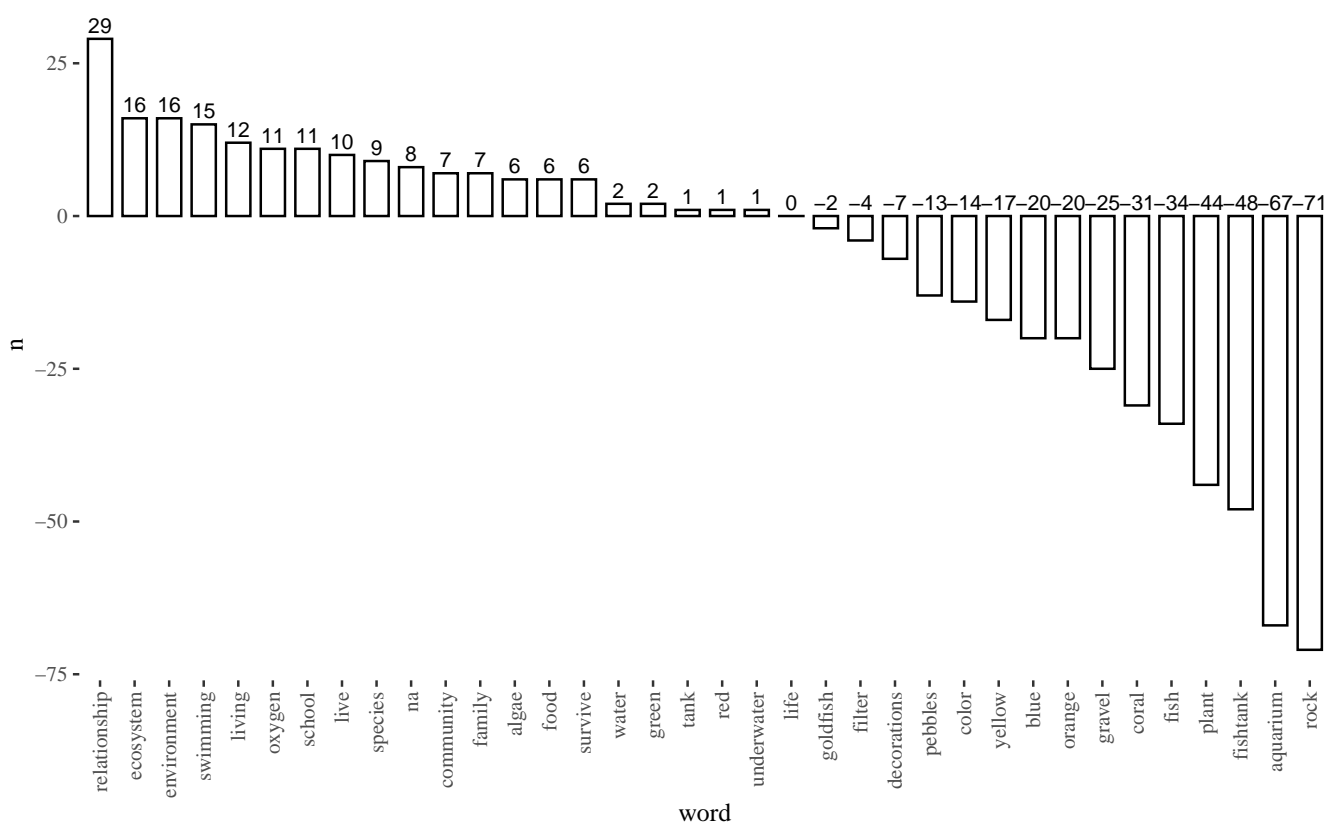

Figure 11. Difference in word count before and after R treatment.

\subsection{Perspectives}

The data for the Perspectives $(\mathrm{P})$ study is shown visually in the comparison of word clouds. Below is the PreP and PostP word cloud comparisons (Table 25).

Table 25. Word cloud of response before and after perspective prompt.

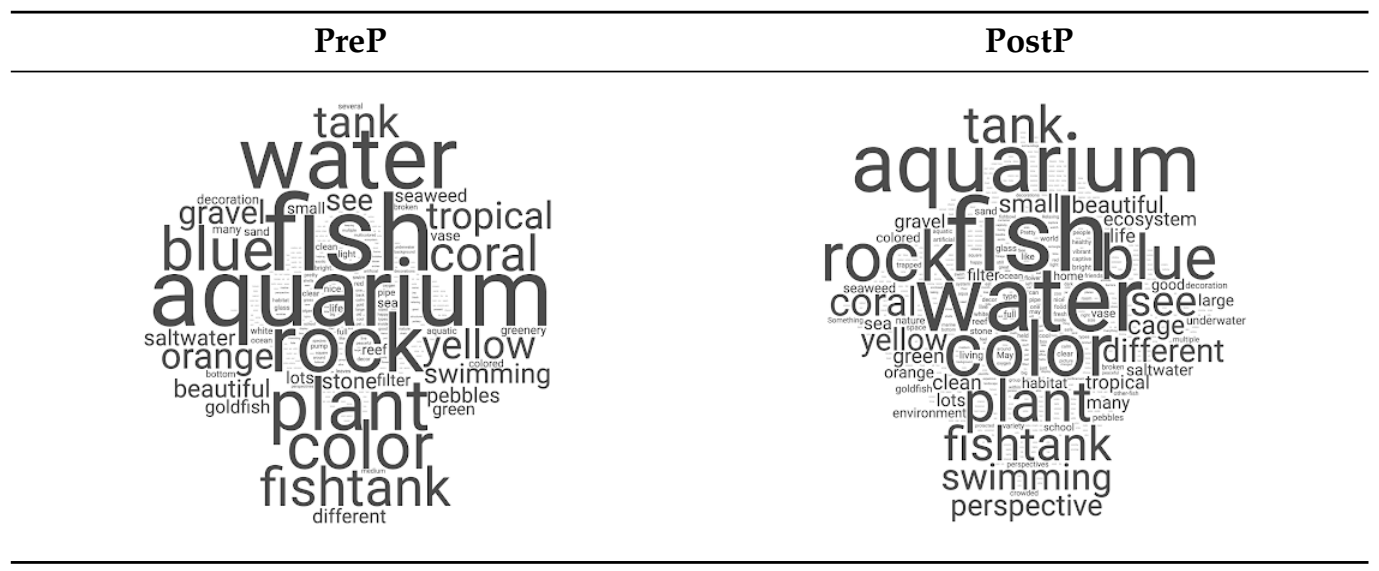

The word clouds show the significant impact of the Perspectives prime. The PostP word cloud is more detailed and more descriptive than the unprimed PreP word cloud. The larger a word is, the more times it is used. There are perspectival words-such as perspectives and see-in the PostP data that are nonexistent in the PreP data. PostP also has more unique words overall. The same patterns shown visually in the word clouds are in the quantitative data as well. The responses in the PostP have significantly more words overall and those words are more perspectival. Table 26 shows the quantitative data analysis.

Table 27 lays out the top 40 words for the PreP and the PostP responses. It also shows their occurrences and percentage of total occurrences. The PostP condition includes many more unique words than the PreP. Perspectival words made up significantly more of the PostP total than in the PreP condition including words like: see (41), perspective (25), and cage (18). 
Table 26. PreP and PostP aggregate response data.

\begin{tabular}{llll}
\hline & PreP & PostP & Difference \\
\hline Number of characters (including spaces) & 19,758 & 22,371 & $+11.68 \%$ \\
Number of characters (without spaces) & 12,336 & 13,794 & $+10.57 \%$ \\
Number of words (including repeated words) & 2513 & 2915 & $+13.79 \%$ \\
Number of syllables (including repeated words) & 3967 & 4483 & $+11.51 \%$ \\
Unique words & 276 & 497 & $+44.47 \%$ \\
Number of characters (no spaces) for unique words & 1598 & 2914 & $+45.16 \%$ \\
Number of syllables for unique words & 533 & 991 & $+46.22 \%$ \\
Total unique words occurrence & 2089 & 2322 & $+10.03 \%$ \\
\hline
\end{tabular}

Table 27. PreP and PostP top 40 terms used.

\begin{tabular}{|c|c|c|c|c|c|c|}
\hline \multirow[b]{2}{*}{ Rank } & \multicolumn{3}{|c|}{ PreP (Total 2089) } & \multicolumn{3}{|c|}{ PostP (Total 2322) } \\
\hline & Word & Occurs & $\%$ & Word & Occurs & $\%$ \\
\hline 1 & fish & 403 & $19.29 \%$ & fish & 350 & $15.07 \%$ \\
\hline 2 & aquarium & 142 & $6.80 \%$ & water & 106 & $4.57 \%$ \\
\hline 3 & water & 138 & $6.61 \%$ & aquarium & 90 & $3.88 \%$ \\
\hline 4 & rock & 97 & $4.64 \%$ & color & 86 & $3.70 \%$ \\
\hline 5 & color & 94 & $4.50 \%$ & rock & 57 & $2.45 \%$ \\
\hline 6 & plant & 88 & $4.21 \%$ & blue & 48 & $2.07 \%$ \\
\hline 7 & blue & 68 & $3.26 \%$ & plant & 45 & $1.94 \%$ \\
\hline 8 & fish tank & 60 & $2.87 \%$ & tank & 42 & $1.81 \%$ \\
\hline 9 & coral & 51 & $2.44 \%$ & see & 41 & $1.77 \%$ \\
\hline 10 & $\operatorname{tank}$ & 45 & $2.15 \%$ & fish tank & 38 & $1.64 \%$ \\
\hline 11 & yellow & 37 & $1.77 \%$ & swimming & 29 & $1.25 \%$ \\
\hline 12 & orange & 28 & $1.28 \%$ & coral & 26 & $1.12 \%$ \\
\hline 13 & tropical & 28 & $1.34 \%$ & perspective & 25 & $1.08 \%$ \\
\hline 14 & gravel & 27 & $1.29 \%$ & with & 23 & $0.99 \%$ \\
\hline 15 & many & 24 & $1.15 \%$ & different & 22 & $0.95 \%$ \\
\hline 16 & see & 23 & $1.10 \%$ & yellow & 21 & $0.90 \%$ \\
\hline 17 & swimming & 21 & $1.01 \%$ & cage & 18 & $0.78 \%$ \\
\hline 18 & beautiful & 18 & $0.86 \%$ & small & 18 & $0.78 \%$ \\
\hline 19 & pebbles & 17 & $0.81 \%$ & beautiful & 17 & $0.73 \%$ \\
\hline 20 & saltwater & 16 & $0.77 \%$ & be & 16 & $0.69 \%$ \\
\hline 21 & stone & 16 & $0.77 \%$ & clean & 15 & $0.65 \%$ \\
\hline 22 & different & 15 & $0.72 \%$ & ecosystem & 15 & $0.65 \%$ \\
\hline 23 & goldfish & 15 & $0.72 \%$ & there & 15 & $0.65 \%$ \\
\hline 24 & seaweed & 15 & $0.72 \%$ & decoration & 14 & $0.60 \%$ \\
\hline 25 & decoration & 13 & $0.62 \%$ & green & 14 & $0.60 \%$ \\
\hline 26 & filter & 13 & $0.62 \%$ & gravel & 13 & $0.56 \%$ \\
\hline 27 & green & 13 & $0.62 \%$ & life & 13 & $0.56 \%$ \\
\hline 28 & small & 12 & $0.57 \%$ & tropical & 13 & $0.56 \%$ \\
\hline 29 & reef & 11 & $0.53 \%$ & filter & 12 & $0.52 \%$ \\
\hline 30 & vase & 11 & $0.53 \%$ & lots & 12 & $0.52 \%$ \\
\hline 31 & greenery & 10 & $0.48 \%$ & many & 12 & $0.52 \%$ \\
\hline 32 & sand & 9 & $0.43 \%$ & other & 12 & $0.52 \%$ \\
\hline 33 & some & 9 & $0.43 \%$ & sea & 12 & $0.52 \%$ \\
\hline 34 & life & 8 & $0.38 \%$ & large & 11 & $0.47 \%$ \\
\hline 35 & sea & 8 & $0.38 \%$ & orange & 11 & $0.47 \%$ \\
\hline 36 & aquatic & 7 & $0.34 \%$ & saltwater & 11 & $0.47 \%$ \\
\hline 37 & bottom & 7 & $0.34 \%$ & that & 11 & $0.47 \%$ \\
\hline 38 & clean & 7 & $0.34 \%$ & environment & 10 & $0.43 \%$ \\
\hline 39 & light & 7 & $0.34 \%$ & habitat & 10 & $0.43 \%$ \\
\hline 40 & nice & 7 & $0.34 \%$ & home & 10 & $0.43 \%$ \\
\hline
\end{tabular}

Data $(\mathrm{N}=362)$ were summarized using median (IQR). Statistical analysis was performed using Wilcoxon-signed rank test. Results in Figures 12-14 and Table 28 show that the distribution of concepts was significantly different before and after treatment 
( $p=0.002^{* *}$ using Wilcoxon signed-rank test) with a lower average number of concepts observed after treatment. The median number of words used after treatment ( $\mathrm{Mdn}=6$, IQR 3-10) was significantly higher than the median number of words used before treatment (Mdn $=5$, IQR 3-8, $p=0.064)$ although the result was statistically significant at the 0.1 level. The median number of characters used after treatment (Mdn $=32$, IQR 19-59) was significantly higher than the median number of words used before treatment ( $\mathrm{Mdn}=28$, IQR $18-45, p=0.013^{* *}$ ).

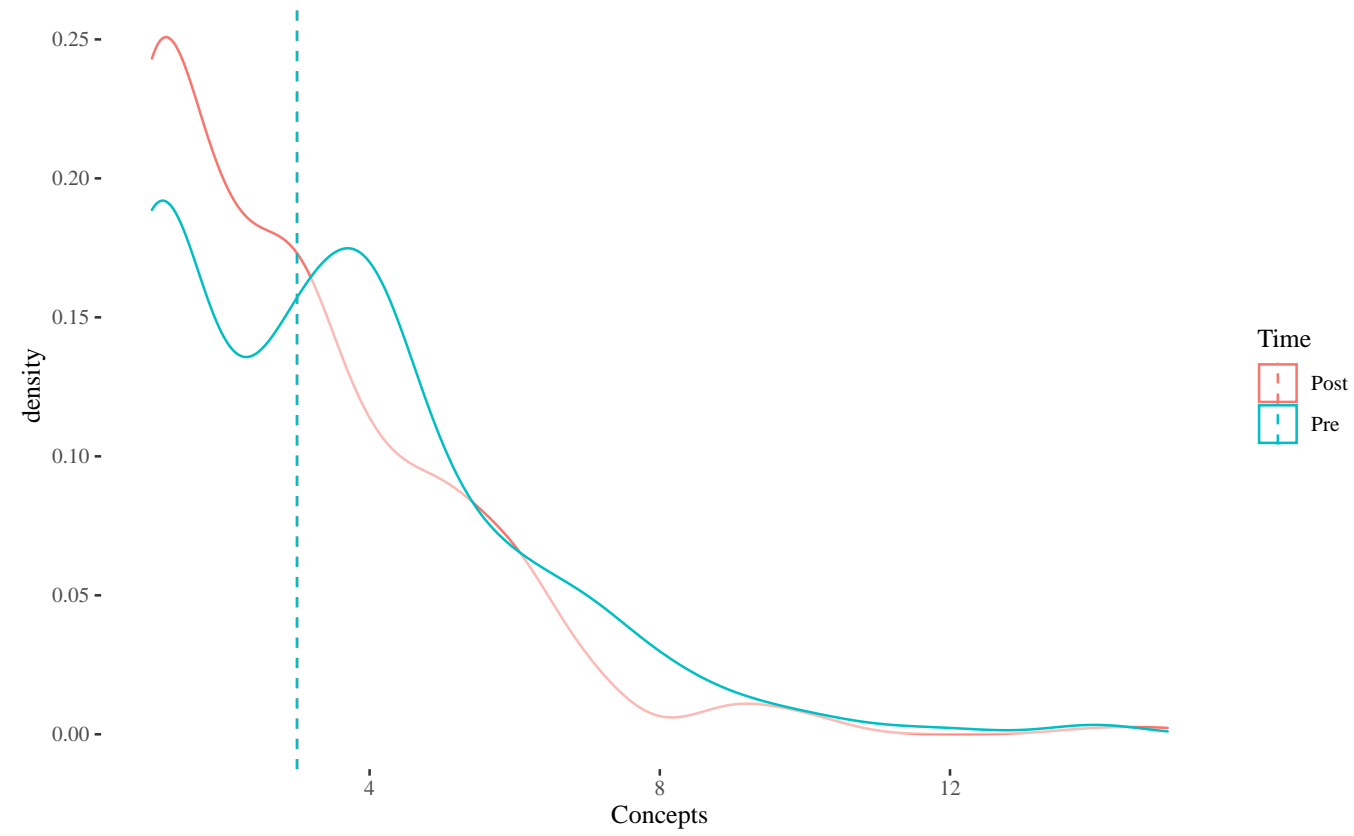

Figure 12. Distribution of concepts for PreP and PostP (vertical lines represent median).

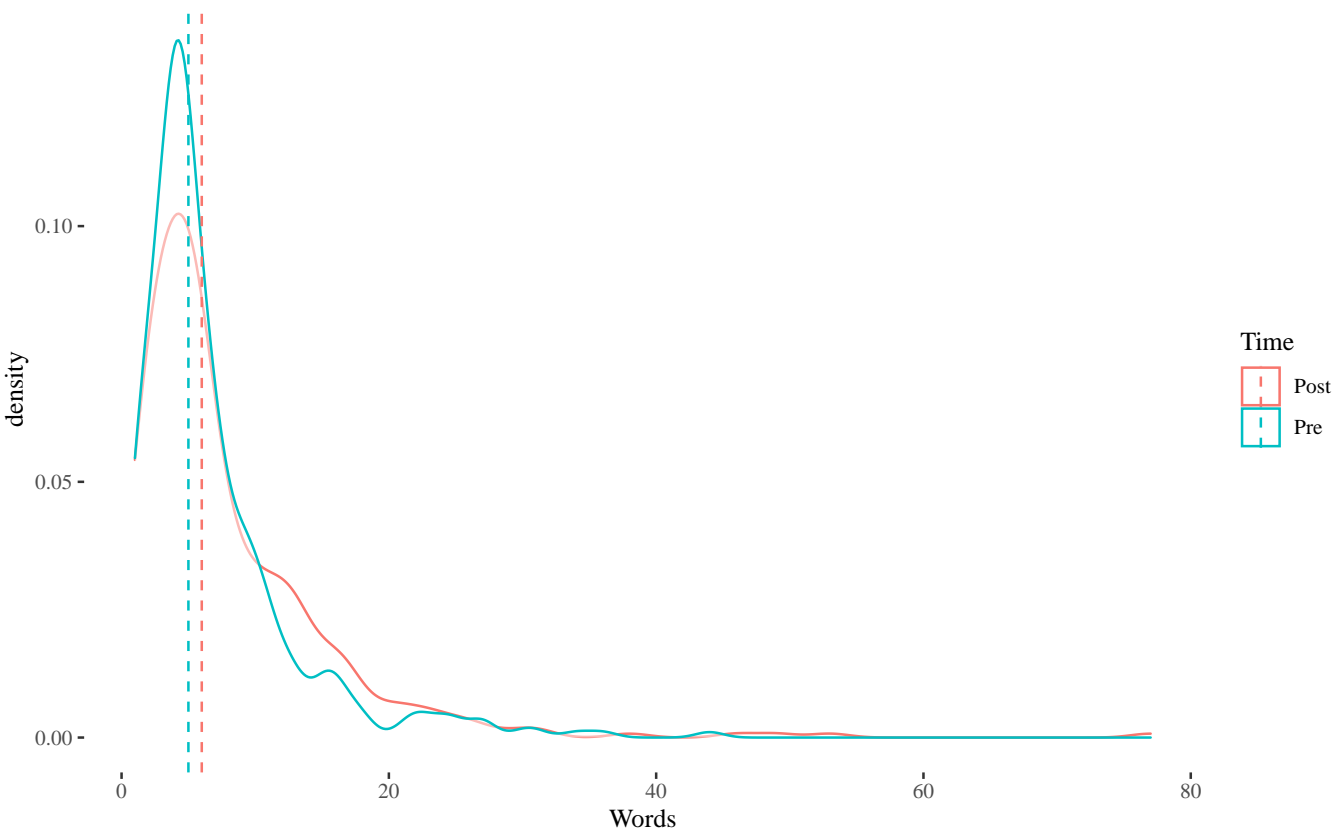

Figure 13. Distribution of words for PreP and PostP (vertical lines represent median). 


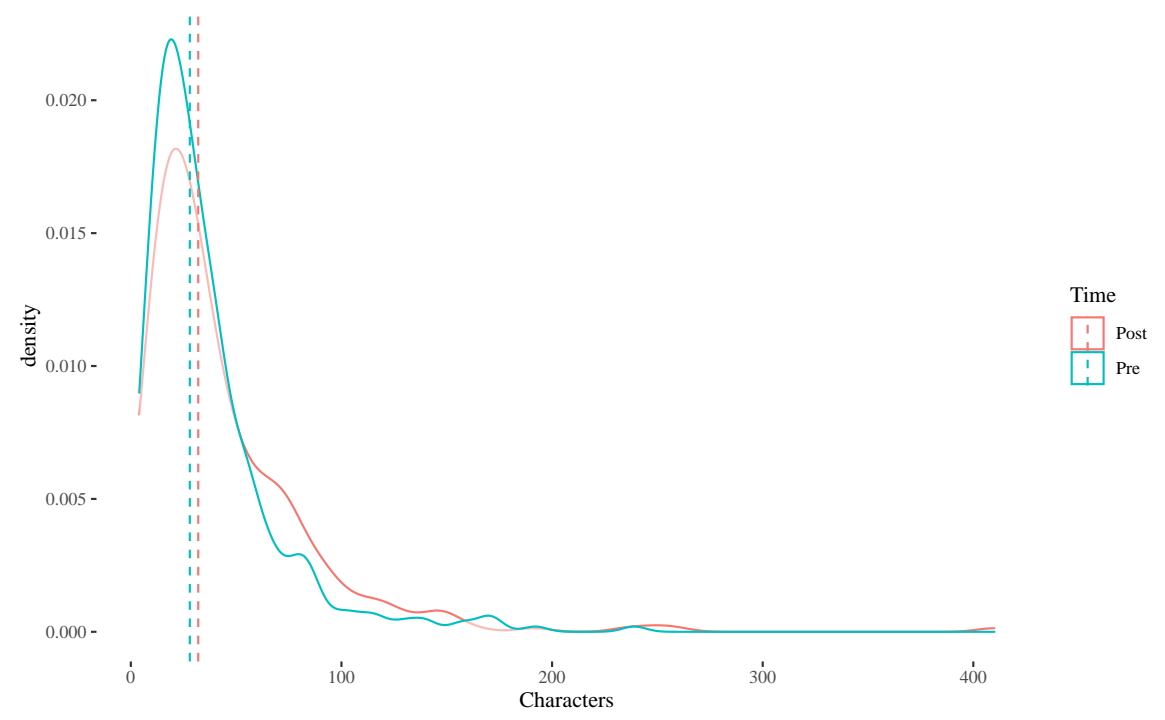

Figure 14. Distribution of characters for PreP and PostP (vertical lines represent median).

Table 28. Comparison of raw counts, words, and characters before and after P treatment.

\begin{tabular}{llll}
\hline & Pre & Post & P.overall \\
\hline No. concepts & & & \\
Median $[\mathrm{IQR}]$ & $3.00[1.00 ; 5.00]$ & $3.00[1.00 ; 4.00]$ & $\mathbf{0 . 0 0 2}$ \\
Mean (SD) & $3.51(2.36)$ & $2.99(2.15)$ & $\mathbf{0 . 0 0 2}$ \\
& $3.00[1.00 ; 4.00]$ & $3.00[1.00 ; 4.00]$ & 0.062 \\
No. words & $5.00[3.00 ; 8.00]$ & $6.00[3.00 ; 10.0]$ & 0.064 \\
No. characters & $28.0[18.0 ; 45.0]$ & $32.0[19.0 ; 58.8]$ & $\mathbf{0 . 0 1 3}$ \\
\hline
\end{tabular}

Figure 15 shows the difference in the use of any given word ( $x$-axis) between Post and Pre. Data were filtered to only include words mentioned more than five times, such that positive numbers indicate higher word counts post treatment. A positive number indicates that the word was used more post treatment while a negative indicates the less post treatment. For example, the word perspective was used 20 more times and the word cage was used 18 more times post-treatment indicating that subjects took perspective more often.

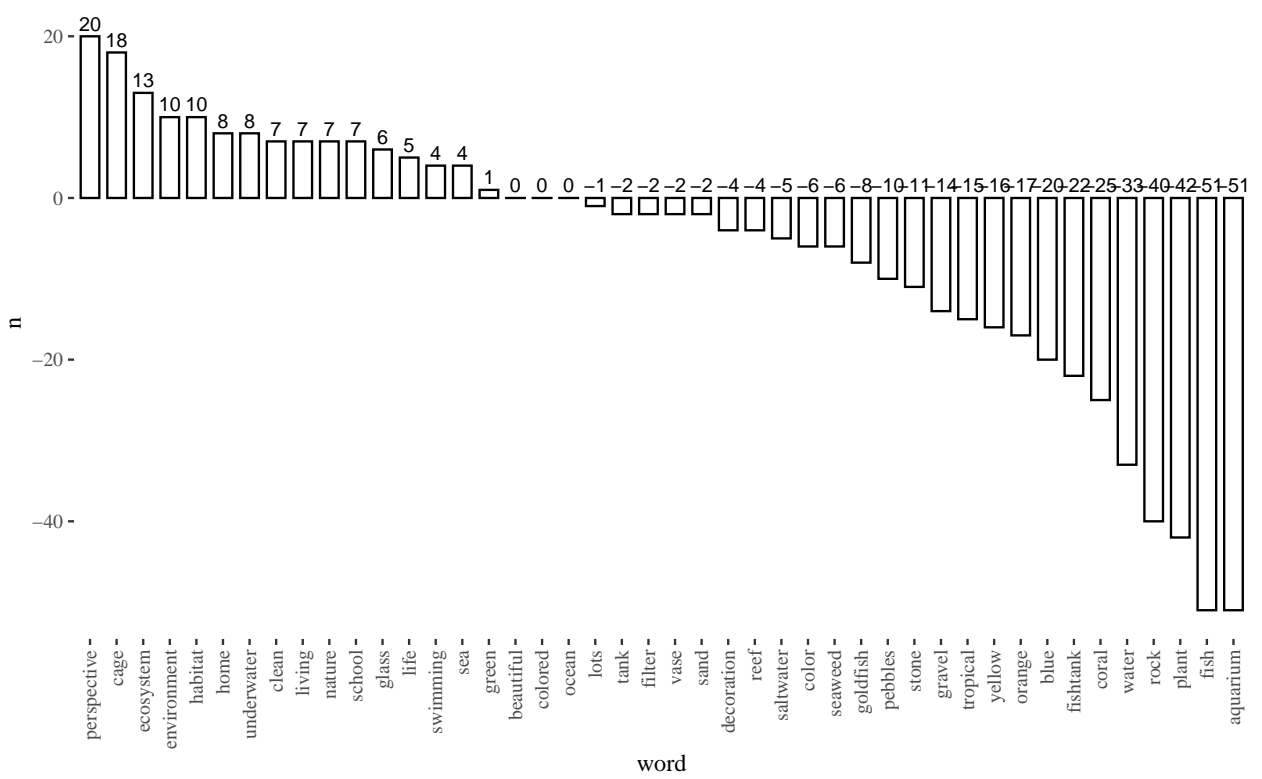

Figure 15. Difference in word count before and after P treatment. 
Data were filtered to words mentioned > five times; positive numbers indicate higher count post treatment. Results showed (Table 29) that the expected number of concepts was significantly lower after treatment than before treatment (IRR $=0.85, p<0.001^{* * *}$ ). However, the expected number of words was higher by $17 \%$ post-treatment than before treatment $\left(\operatorname{IRR}=1.17, p<0.001^{* * *}\right)$. Similarly, the expected number of characters was higher by $19 \%$ post-treatment than pre-treatment $\left(\operatorname{IRR}=1.19, p<0.001^{* * *}\right)$. Male gender, education, age, and ethnicity were not significantly different before and after intervention.

Table 29. P mixed generalized linear regression.

\begin{tabular}{|c|c|c|c|c|c|c|}
\hline Predictors & $\begin{array}{l}\text { No. Concepts } \\
\text { Incidence Rate Ratios }\end{array}$ & $p$ & $\begin{array}{l}\text { No. Words } \\
\text { Incidence Rate Ratios }\end{array}$ & $p$ & $\begin{array}{l}\text { No. Characters } \\
\text { Incidence Rate Ratios }\end{array}$ & $p$ \\
\hline (Intercept) & $4.12(3.25-5.21)$ & $<0.001$ & $4.88(3.68-6.46)$ & $<0.001$ & $25.69(19.66-33.57)$ & $<0.001$ \\
\hline Time (Post vs. Pre) & $0.85(0.79-0.93)$ & $<0.001$ & $1.17(1.09-1.26)$ & $<0.001$ & $1.19(1.11-1.27)$ & $<0.001$ \\
\hline Age (1 level increase) & $0.97(0.95-1.00)$ & 0.051 & $1.01(0.98-1.04)$ & 0.531 & $1.02(0.99-1.05)$ & 0.253 \\
\hline Education (1 level increase) & $1.01(0.97-1.05)$ & 0.688 & $1.02(0.97-1.07)$ & 0.429 & $1.02(0.97-1.06)$ & 0.439 \\
\hline Ethnicity (Not Latino and/or Hispanic) & $0.86(0.71-1.04)$ & 0.128 & $1.11(0.88-1.40)$ & 0.357 & $1.12(0.90-1.40)$ & 0.293 \\
\hline Gender (Male) & $0.91(0.80-1.03)$ & 0.119 & $1.00(0.86-1.15)$ & 0.982 & $1.01(0.88-1.16)$ & 0.837 \\
\hline Marginal $R^{2} /$ Conditional $R^{2}$ & $0.032 / 0.394$ & & $0.015 / 0.573$ & & $0.021 / 0.562$ & \\
\hline
\end{tabular}

\section{Discussion}

Subjects were asked to describe a common scene before and after a simple treatment. The results are statistically unambiguous. However, one should consider some of the alternative explanations or mediating variables. There are a number of such things to consider.

For example, the post-treatment condition is the second time subjects were asked to describe the same scene. Thus, one might expect them-due to familiarity/repetition-to describe the scene with greater complexity. However, this explanation does not account for the increases in unique words, number of characters of unique words, number of syllables for unique words, and total unique words occurrence. As a mediating variable, familiarity/repetition also does not account for the correlation we see in the top words used Pre and Post. In other words, we see more and better post treatment. Familiarity/repetition might account for some aspect of the more, but not the better results. Another way to explain this is that in the post-treatment results, where we saw more and better (both quantitatively and qualitatively), we also saw more of the specific form of thinking: more perspectives, more distinctions, more part-whole structures, more interrelationships. Repetition/familiarity alone would not produce results of this specific nature.

One might also conclude that intentionality or a "social-desirability bias" (a form of response bias) played a role in the post-treatment results. For example, it may be that subjects, in their desire to please the researchers or be seen as "good at the task" simply did more post-treatment than pre-treatment. To assume such a mediating factor would be to grossly misunderstand the application of such bias. If we are surveying an individual, for example, on their drug use, one might reasonably expect an under-reporting due to such a bias. However, in this study, we are testing whether being made aware of a cognitive pattern/structure can effectively increase one's cognitive complexity and the systemic nature of their thinking. In this case, intentionality is precisely what we are seeking to learn the effect of (a.k.a., metacognition). We are seeking to determine whether being made aware of a cognitive pattern-and therefore intentional in one's thinking-produces a positive effect in the result of one's thinking.

Finally, with regard to mediating factors, consider a hypothetical alternative study where the study design is the same but for one change to the treatment. In this hypothetical example, consider two variants:

1. The treatment is something entirely random such as: Look for orange things such as Cheetos, oranges, basketballs, pumpkins or things that remind you of Cheetos, oranges, basketballs, pumpkins, etc.

2. The treatment is something more purposefully cognitive and structural such as: consider the polarizing arguments that could be made about the scene. 
Now consider what we might find in our two hypothetical studies and how those findings would differ from those of this study. In the first study (\#1 above), one would hypothesize that more subjects would focus on and find more orange things. They would perhaps set their intention to discover more orange things in order to please the researchers. Overall, we would see an increase in orange things seen and described. In the second study (\#2 above), one would hypothesize that more subjects would focus on and describe more polarizing aspects of the scene, such as the consideration of animal cruelty vs. pet-loving or agency vs. ownership or saltwater vs. freshwater. They would perhaps set their intention to discover more polarized examples in order to please the researchers. Overall, we would see an increase in the polarized examples described.

In the first hypothetical study, we would get relatively inconsequential results due to the random nature of the treatment. In the second hypothetical study, we would get relatively negative results due to the undesirable nature of the treatment (few of us are seeking ways to increase polarized-thinking). The point of these hypothetical examples is to tease out what is critically important in the fish tank studies described herein: that there is something quite remarkable about the cognitive structures of the treatments. These particular DSRP structures — when used purposefully and metacognitively — are neither random nor do they produce undesirable results, but are instead targeted and produce the desirable results of increased cognitive complexity, sophistication, robustness, and systemic thinking.

As just one of eight dimensions of difference between Pre and Post, Figure 16 shows the stark aggregate change from PreDSRP to PostDSRP (in terms of number of words).

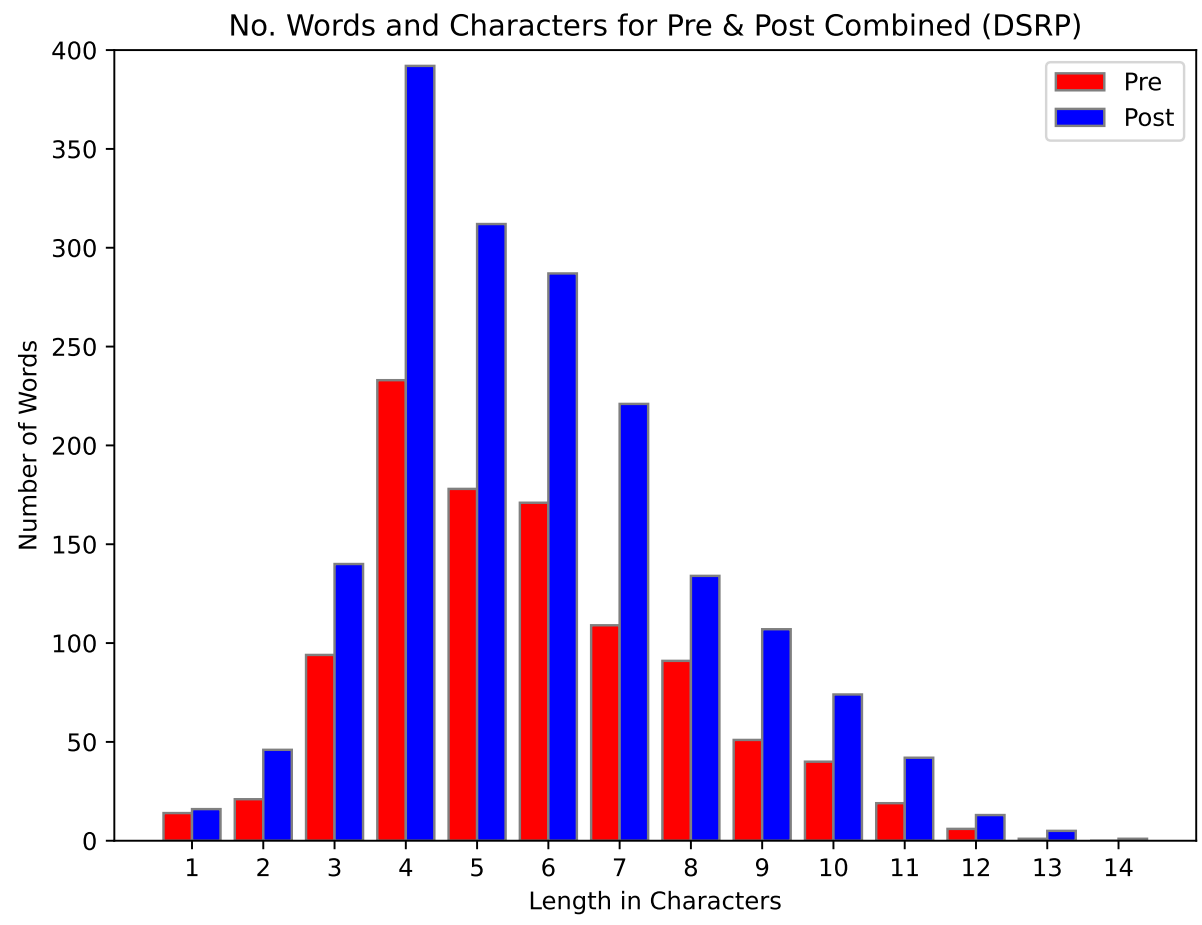

Figure 16. Aggregate DSRP Pre/Post graphical comparison.

Table 30 shows a summary of $p$-values across all four D, S, R, and P studies. 
Table 30. Summary $p$-values for $\mathrm{D}, \mathrm{S}, \mathrm{R}$, and P Pre and Post treatments.

\begin{tabular}{ll}
\hline & $p$ \\
\hline Identity-Other Distinctions (D) & \\
\hline No. concepts & 0.062 \\
No. words & $<0.001$ \\
No. characters & $<\mathbf{0 . 0 0 1}$ \\
\hline Part-Whole Systems (S) & \\
\hline No. concepts & $<\mathbf{0 . 0 0 1}$ \\
No. words & 0.13 \\
No. characters & 0.13 \\
\hline Action-Reaction Relationships (R) & \\
\hline No. concepts & $<\mathbf{0 . 0 0 1}$ \\
No. words & $\mathbf{0 . 0 0 3}$ \\
No. characters & $\mathbf{0 . 0 1 5}$ \\
\hline Point-View Perspectives (P) & \\
\hline No. concepts & $\mathbf{0 . 0 0 2}$ \\
No. words & 0.064 \\
No. characters & $\mathbf{0 . 0 1 3}$ \\
\hline
\end{tabular}

Table 31 summarizes the aggregate differences along eight dimensions across all four $\mathrm{D}, \mathrm{S}, \mathrm{R}$, and P studies showing a stark difference in the rows and columns of increases $(+\mathrm{s})$. The percentages are the result of of Post minus Pre aggregates.

Table 31. Difference for Pre and Post D, S, R, and P.

\begin{tabular}{|c|c|c|c|c|}
\hline & D & $\mathbf{S}$ & $\mathbf{R}$ & $\mathbf{P}$ \\
\hline Number of characters (including spaces) & $+27.22 \%$ & $+11.91 \%$ & $+16.03 \%$ & $+11.68 \%$ \\
\hline Number of characters (without spaces) & $+30.24 \%$ & $+09.09 \%$ & $+14.17 \%$ & $+10.57 \%$ \\
\hline Number of words (including repeated words) & $+31.68 \%$ & $+13.20 \%$ & $+20.11 \%$ & $+13.79 \%$ \\
\hline Number of syllables (including repeated words) & $+28.78 \%$ & $+12.23 \%$ & $+20.11 \%$ & $+11.51 \%$ \\
\hline Unique words & $+44.59 \%$ & $+41.59 \%$ & $+40.13 \%$ & $+44.47 \%$ \\
\hline Number of characters (no spaces) for unique words & $+46.00 \%$ & $+49.21 \%$ & $+41.21 \%$ & $+45.16 \%$ \\
\hline Number of syllables for unique words & $+45.39 \%$ & $+43.00 \%$ & $+42.01 \%$ & $+46.22 \%$ \\
\hline Total unique words occurrence & $+31.64 \%$ & $+04.88 \%$ & $+16.26 \%$ & $+10.03 \%$ \\
\hline
\end{tabular}

\subsection{Distinctions}

In Table 30, p-value results for Distinctions (D) indicate that there was statistically significant difference in individual subjects in the number of concepts they answered at the 0.1 level. Additionally, there was a highly statistically significant differences in both the number of words and characters. In addition, overall counts (in Table 31) in eight different categories of response data increased. This leads us to conclude that the very short treatment had a significant effect on the participant's cognitive complexity. Figure 17 graphically represents the difference between the PreD and PostD data.

These findings indicate highly statistically significant and statistically significant increases in the degree to which people made more detailed distinctions and more distinctions from just a $<1$ min treatment. The implications this research has on metacognition and its relationship to cognitive complexity is substantial. 


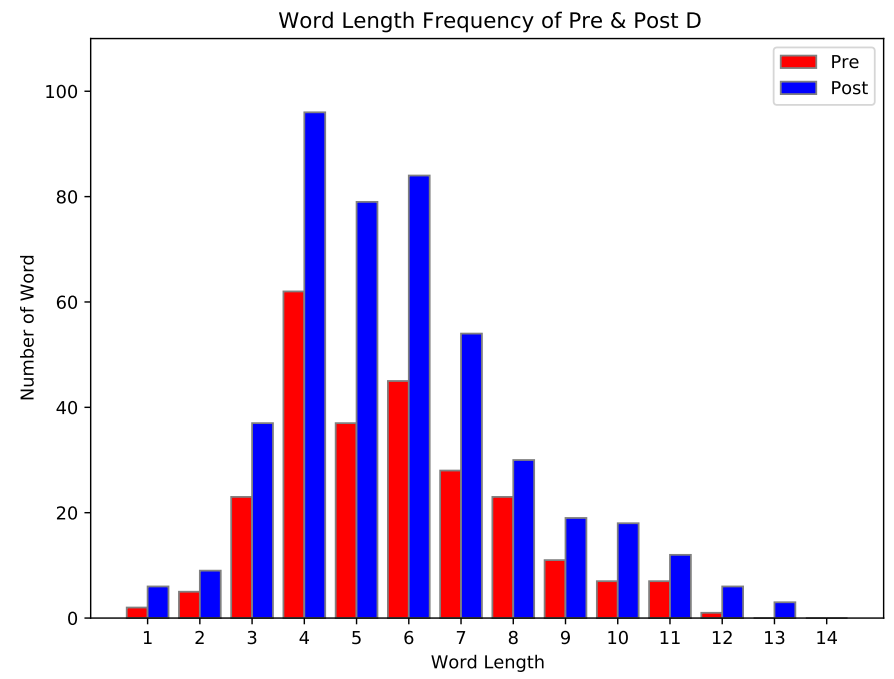

Figure 17. Comparison of PreD and PostD data.

\subsection{Systems}

In Table 30, $p$-value results for Systems (S) indicate that there was a highly statistically significant difference in individual subjects in the number of concepts they answered, but not in the number of words and characters. This is most likely because listing additional parts would not require additional words and characters (e.g., complexity). For example, listing that a fish had a part "fin" increases the number of concepts but not necessarily words and characters. At the same time, overall counts (in Table 31) in eight different categories of response data increased. This leads us to conclude that the very short treatment had a significant effect on the participant's cognitive complexity.

Figure 18 shows the graphical representation of the difference between the PreS and PostS data.

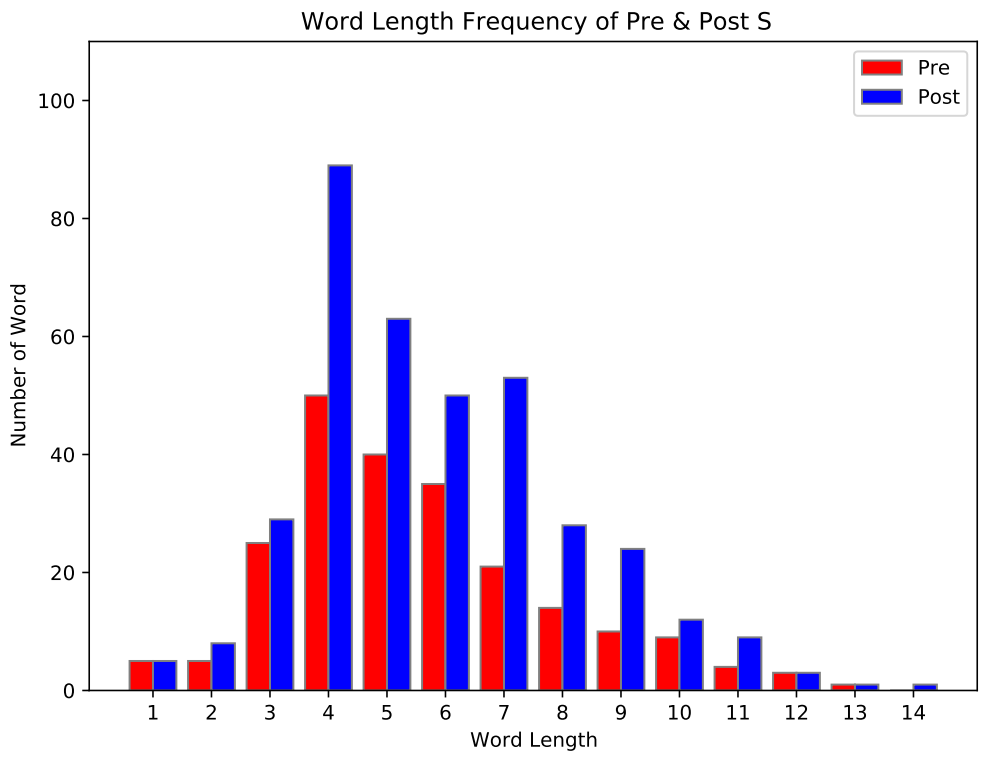

Figure 18. Comparison of PreS and PostS data.

These findings indicate highly statistically significant and statistically significant increases in the degree to which people made more systemic answers from just a $<1$ min treatment. 
Again, the implications this research has on metacognition and its relationship to cognitive complexity is substantial.

\subsection{Relationships}

Relationship (R) results in Table 30, show $p$-value results that indicate that there was highly statistically significant difference in individual subjects in the number of concepts, words, and characters. In addition, overall counts (in Table 31) in eight different categories of response data increased. This leads us to conclude that the very short treatment had a significant effect on the participant's cognitive complexity. Figure 19 shows the graphical representation of the difference between the PreR and PostR data.

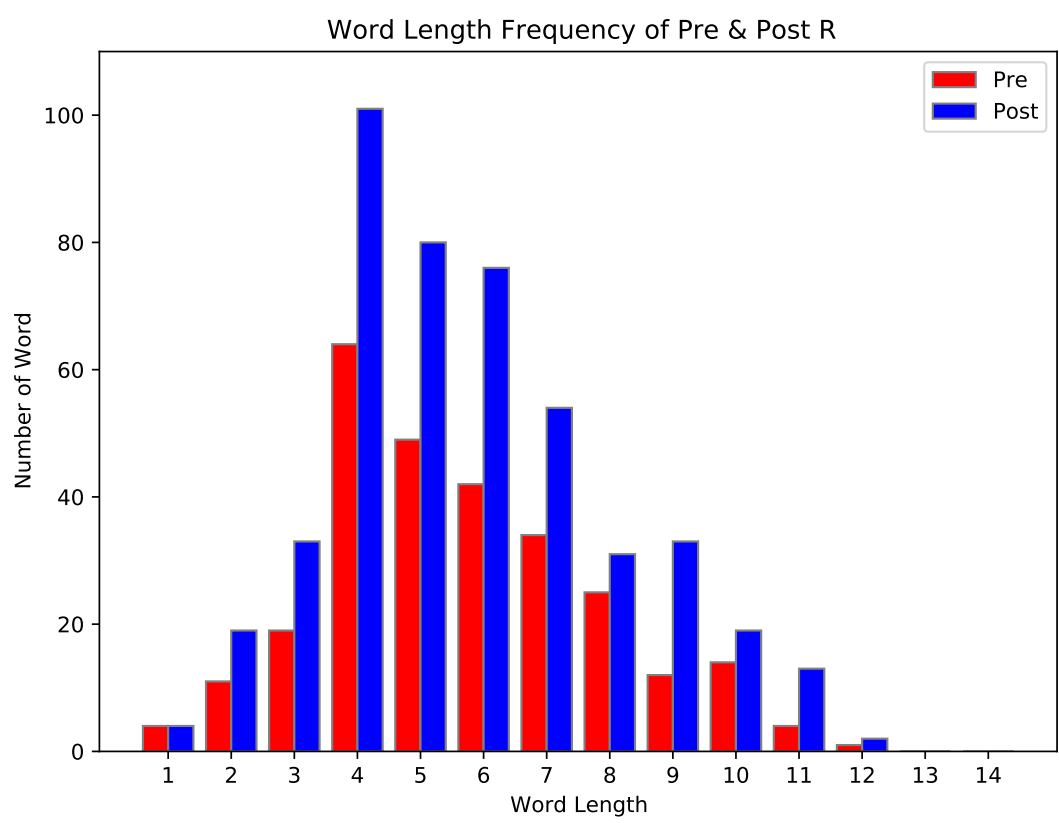

Figure 19. Comparison of PreR and PostR data.

These findings indicate highly statistically significant increases in the degree to which people made more interrelational answers from just a $<1$ min treatment. Again, the implications this research has on metacognition and its relationship to cognitive complexity is substantial.

\subsection{Perspectives}

Perspective $(\mathrm{P})$ results in Table 30, show $p$-value results that indicate that there was statistically significant difference in individual subjects in the number of concepts and characters but not words. In addition, overall counts (in Table 31) in eight different categories of response data increased. This leads us to conclude that the very short treatment had a significant effect on the participant's cognitive complexity. Figure 20 shows the graphical representation of the difference between the PreP and PostP data.

These findings indicate statistically significant increases in the degree to which people made take perspectives from just a $<1$ min treatment. Again, the implications this research has on metacognition of DSRP and its relationship to systems thinking and cognitive complexity are substantial. 


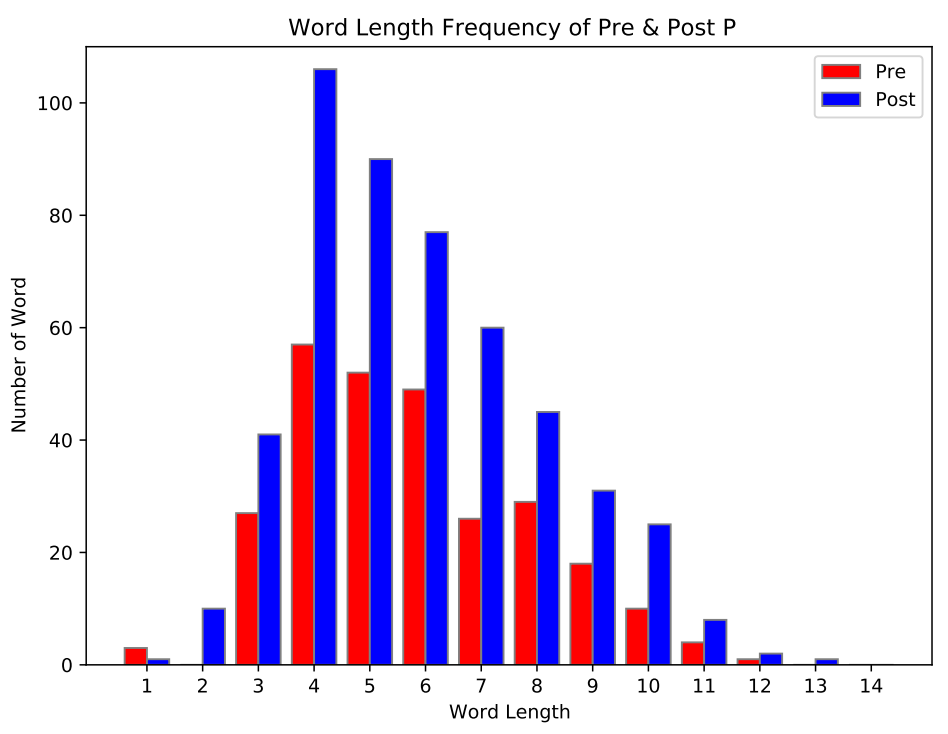

Figure 20. Comparison of PreP and PostP data.

Although it was not the primary focus of this study, there were no statistically significant differences Pre and Post for D, S, R, or P treatments based on either ethnicity or education. This indicates that DSRP is not effected by education or ethnicity, which is interesting given that most "educational" treatments would differ based on ethnicity (e.g., systemic racism in test scores) and education level (e.g., systemic racism in educational attainment $)^{3}$. Whereas, there was a significant difference in $\mathrm{S}$ and $\mathrm{R}$ for younger individuals, suggesting that DSRP abilities may increase with life experience. There were also significant decreases in D, S, and R for males. Although further research is needed to determine the full scope and meaning of these results, these data may suggest that DSRP is egalitarian.

\section{Conclusions}

As a whole, these findings indicate both highly statistically significant and statistically significant increases cognitive complexity from a $<1$ min treatment. The PostD, PostS, PostR, and PostP studies substantially differ from the PreD, PreS, PreR, and PreP studies, respectively. We can conclude that:

1. people trained in Distinction-making will have more detailed and specific thoughts, whereas;

2. people trained in Systems-organizing will create more hierarchical structures and scale their thoughts up and down past the visual/conceptual question;

3. people trained in Relationship building will create and identify more and better interrelationships, and;

4. people trained in seeing Perspectives will see the stimulus from multiple points of view.

The implications this research has on metacognition and its relationship to cognitive complexity are substantial, especially when considering the very short and relatively shallow treatment. With a more substantive treatment, such as $1 \mathrm{~h}$ or 1 semester training (i.e., the training norm) the effects may be truly transformative. Future studies might vary the depth and length of the treatment or focus the treatment on sub-aspects of the $D, S, R$, or P patterns or elements, or on combinations thereof. In addition, similar studies could be undertaken in more specialized domains with demographically or psychographically specialized samples, rather than the general sample and content domain chosen for this study for the purpose of generalizability. 
The plethora of different analyses of these data in this collection of studies clearly demonstrate that a short treatment of D, S, R, or P has both highly statistically significant and statistically significant effect on a participant's cognitive and conceptual complexity. The "Fish Tank" experiments show that less than one minute of reading bulleted text can change a person's thinking significantly. Further, the Fish Tank experiments show that the awareness of the universal patterns of mind (DSRP) improves the quality and quantity of a person's observations.

Author Contributions: All authors contributed equally in methodology, software, validation, formal analysis, investigation, resources, data curation, writing — original draft preparation, writing - review and editing, visualization, supervision, project administration, funding acquisition. Development of DSRP Theory, D.C. All authors have read and agreed to the published version of the manuscript.

Funding: This research received no external funding.

Institutional Review Board Statement: Ethical review and approval were waived for this study, due to no collection of personal or identifying data.

Informed Consent Statement: Informed consent was obtained from all subjects involved in the study.

Data Availability Statement: The data presented in this study are available on request from the corresponding author. The data are not publicly available due to privacy, human subjects, and ethical considerations.

Conflicts of Interest: The authors declare no conflict of interest.

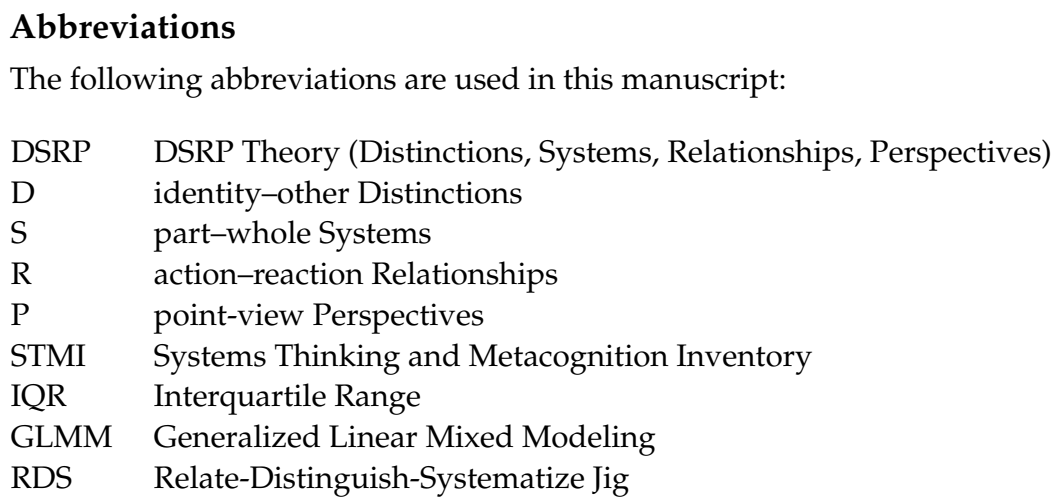

\section{Notes}

1 We would use the words "gap in the research here" but a gap implies something missing between two existing things. Whereas a dearth is a scarcity or lack of something altogether.

2 It should be noted that the ST/DSRP Loop is the mirror opposite of confirmation bias. Confirmation bias reverses this loop, by fitting reality to one's mental models, whereas DSRP Systems Thinking fits mental models to real-world observables and feedback. Parallelism is therefore the degree to which one's cognitive paradigm, style, or mindset, aligns with nature's. One purpose of this research program is to determine the degree to which DSRP Theory accomplishes this parallelism.

3 In other words, Black, Hispanic and Native Americans statistically tend to be disadvantaged when it comes to educational attainment and get lower test scores overall than White or Asians Americans [161,162].

\section{References}

1. Cabrera, D. Systems Thinking; Cornell University: Ithaca, NY, USA, 2006.

2. Cabrera, D.; Cabrera, L.; Midgley, G. (Eds.) The Four Waves of Systems Thinking. In Routledge Handbook of Systems Thinking; Routledge: London, UK, 2022; under process.

3. Cabrera, D.; Cabrera, L.; Cabrera, E.; Hernandez, O.; Sukhbaatar, U.; Fuqua, K.; Benitez Collante, A.E.; Lemaiyan, E.; Warugongo, N.; Sekyere, A.; et al. The Origin of Ideas: Empirical Studies in Cognitive Complexity; Odyssean Press: Ithaca, NY, USA, 2022.

4. Cabrera, D. Distinctions, Systems, Relationships, Perspectives: The simple rules of complex conceptual systems. In Proceedings of the 52nd Annual Conference of the International Society for the Systems ScInternational Society for the Systems Sciences, Madison, WI, USA, 13-18 July 2008; Volume 1. 
5. Cabrera, D.; Cabrera, L. Systems Thinking Made Simple: New Hope for Solving Wicked Problems in a Complex World; Odyssean Press: Ithaca, NY, USA, 2015.

6. Cabrera, D.; Cabrera, L.; Lobdell, C. Systems Thinking. J. Eval. Program Plan. 2008, 31, 299-310. [CrossRef] [PubMed]

7. Cabrera, D.; Cabrera, L. Complexity and Systems Thinking Models in Education: Applications for Leaders. In Learning, Design, and Technology: An International Compendium of Theory, Research, Practice, and Policy; Spector, M.J., Lockee, B.B., Childress, M.D., Eds.; Springer International Publishing: Cham, Switzerland, 2019; pp. 1-29.

8. Cabrera, D.; Cabrera, L. What Is Systems Thinking? In Learning, Design, and Technology: An International Compendium of Theory, Research, Practice, and Policy; Spector, M.J., Lockee, B.B., Childress, M.D., Eds.; Springer International Publishing: Cham, Switzerland, 2019; pp. 1-28.

9. Cabrera, L.; Cabrera, D. The Simple Rules of Complex Networks: Heuristics for Structural Predictions. In The Routledge Handbook for Systems Thinking; Cabrera, L., Cabrera, D., Midgley, G., Eds.; Routledge Press: London, UK, 2022.

10. Cabrera, D.; Cabrera, L. Distinctions, Systems, Relationships, and Perspectives (DSRP): A Theory of Thinking and of Things. J. Eval. Program Plan. 2008, 31, 311-317. [CrossRef] [PubMed]

11. Cabrera, D.; Cabrera, L. DSRP Theory: A Primer. Systems 2022, 10, 26. [CrossRef]

12. Cabrera, D.; Cabrera, L.; Cabrera, E. A Literature Review of the Universal Patterns and Atomic Elements of Complex Cognition In The Handbook of Systems Thinking; Cabrera, D., Cabrera, L., Midgley, G., Eds.; Routledge: London, UK, 2022.

13. Cabrera, L.; Sokolow, J.; Cabrera, D. Developing and Validating a Measurement of Systems Thinking: The Systems Thinking and Metacognitive Inventory (STMI). In The Routledge Handbook for Systems Thinking; Cabrera, L., Cabrera, D., Midgley, G., Eds.; Routledge Press: London, UK, 2021.

14. Cabrera, D.; Cabrera, L.; Cabrera, E. Perspectives Organize Information in Mind and Nature: Empirical Findings of Point-View Perspective (P) in Cognitive and Material Complexity. Systems 2022, under process.

15. Cabrera, D.; Cabrera, L.; Cabrera, E. Distinctions Organize Information in Mind and Nature: Empirical Findings of Identity-Other Distinctions (D) in Cognitive and Material Complexity. Systems 2022, under process.

16. Cabrera, D.; Cabrera, L.; Cabrera, E. Relationships Organize Information in Mind and Nature: Empirical Findings of ActionReaction Relationships (R) in Cognitive and Material Complexity. Systems 2022, under process.

17. Cabrera, D.; Cabrera, L.; Cabrera, E. Systems Organize Information in Mind and Nature: Empirical Findings of Part-Whole Systems (S) in Cognitive and Material Complexity. Systems 2022, under process.

18. Cabrera, D.; Cabrera, L.; Midgley, G. (Eds.) Routledge Handbook of Systems Thinking; Routledge: London, UK, 2021. [CrossRef]

19. Spencer-Brown, G. Laws of Form; Allen \& Unwin: London, UK, 1969.

20. Krauss, L. Why Is There Something Instead of Nothing?; Simon and Schuster: New York, NY, USA, 2012.

21. Euler, L. Solutio problematis ad geometriam situs pertinentis. Comment. Acad. Sci. Petropol. 1735. 8, $128-140$.

22. Kolata, G. Studying Learning In The Womb. Science 1984, 225, 302-303. [CrossRef]

23. Partanen, E.; Kujala, T.; Näätänen, R.; Liitola, A.; Sambeth, A.; Huotilainen, M. Learning-induced neural plasticity of speech processing before birth. Proc. Natl. Acad. Sci. USA 2013, 110, 15145-15150. [CrossRef]

24. Quinn, P.C.; Brown, C.R.; Streppa, M.L. Perceptual organization of complex visual configurations by young infants. Infant Behav. Dev. 1997, 20, 35-46. [CrossRef]

25. Newman, R.S.; Jusczyk, P.W. The cocktail party effect in infants. Percept. Psychophys. 1996, 58, 1145-1156. [CrossRef] [PubMed]

26. Gauthier, I.; Tarr, M.J. Becoming a “Greeble” expert: Exploring mechanisms for face recognition. Vision Res. 1997, 37, 1673-1682. [CrossRef]

27. Aubin, T.; Jouventin, P. Cocktail-party effect in king penguin colonies. Proc. R. Soc. Lond. Ser. B-Biol. Sci. 1998, 265, 1665-1673. [CrossRef]

28. Fry, S.N.; Wehner, R. Honey bees store landmarks in an egocentric frame of reference. J. Comp. Physiol. A-Neuroethol. Sens. Neural Behav. Physiol. 2002, 187, 1009-1016. [CrossRef] [PubMed]

29. Badre, D. Cognitive control, hierarchy, and the rostro-caudal organization of the frontal lobes. Trends Cogn. Sci. 2008, 12, 193-200. [CrossRef]

30. Bukach, C.M.; Gauthier, I.; Tarr, M.J.; Kadlec, H.; Barth, S.; Ryan, E.; Turpin, J.; Bub, D.N. Does acquisition of Greeble expertise in prosopagnosia rule out a domain-general deficit? Neuropsychologia 2012, 50, 289-304. [CrossRef]

31. Drews, G. Contributions of Theodor Wilhelm Engelmann on phototaxis, chemotaxis, and photosynthesis. Photosynth. Res. 2005, 83, 25-34. [CrossRef]

32. Sengupta, A.; Kruppa, T.; Löwen, H. Chemotactic predator-prey dynamics. Phys. Rev. E 2010, 83, 031914. [CrossRef]

33. Berleman, J.E.; Kirby, J.R. Deciphering the hunting strategy of a bacterial wolfpack. FEMS Microbiol. Rev. 2009, 33, 942-957. [CrossRef]

34. Pradel, E.; Zhang, Y.; Pujol, N.; Matsuyama, T.; Bargmann, C.I.; Ewbank, J.J. Detection and avoidance of a natural product from the pathogenic bacterium Serratia marcescens by Caenorhabditis elegans. Proc. Natl. Acad. Sci. USA 2007, 104, 2295-2300. [CrossRef] [PubMed]

35. Rajalingham, R.; DiCarlo, J.J. Reversible Inactivation of Different Millimeter-Scale Regions of Primate IT Results in Different Patterns of Core Object Recognition Deficits. Neuron 2019, 102, 493-505.e5. [CrossRef]

36. Clark, T. National boundaries, border zones, and marketing strategy: A conceptual framework and theoretical model of secondary boundary effects. J. Mark. 1994, 58, 67-80. [CrossRef] 
37. Coye, D. The Sneakers/Tennis Shoes Boundary. American Speech 1986, 61, 366-369. [CrossRef]

38. Powers, E.; Cabrera, L.; Cabrera, D. No Word Is an Island: Distinguishing "Nerd" and "Geek". Cognitive Case Study; Cornell University: Ithaca, NY, USA, 2016.

39. Peterson, M.A.; Skow-Grant, E. Memory and Learning in Figure-Ground Perception. In Psychology of Learning and Motivation; Academic Press: Cambridge, MA, USA, 2003.

40. Abdullah, M.H.; Klypin, A.; Wilson, G. Cosmological Constraints on $\Omega \mathrm{m}$ and $\sigma 8$ from Cluster Abundances Using the GalWCat19 Optical-spectroscopic SDSS Catalog. Astrophys. J. 2020, 901, 90. [CrossRef]

41. De Luca Picione, R.; Valsiner, J. Psychological Functions of Semiotic Borders in Sense-Making: Liminality of Narrative Processes Eur. J. Psychol. Assess. 2017, 13, 532-547. [CrossRef]

42. Glanville, R. The Self and the Other: The Purpose of Distinction. In Cybernetics and Systems '90, Proceedings of the European Meeting on Cybernetics and Systems Research, Singapore, 17-20 April 1999; World Scientific: Singapore, 1999.

43. Durand, R.; Calori, R. Sameness, Otherness? Enriching Organizational Change Theories With Philosophical Considerations On The Same And The Other. AMRO 2006, 31, 93-114. [CrossRef]

44. Gillette, J.M. Boundary Lines of Social Phenomena. Am. J. Sociol. 1925, 30, 585-593. [CrossRef]

45. Tajfel, H.; Wilkes, A.L. Classification and quantitative judgement. Br. J. Psychol. 1963, 54, 101-114. [CrossRef]

46. Davies, C. Sexual Taboos and Social Boundaries. Am. J. Sociol. 1982, 87, 1032-1063. [CrossRef]

47. Langer, E.J.; Bashner, R.S.; Chanowitz, B. Decreasing prejudice by increasing discrimination. J. Personal. Soc. Psychol. 1985, $49,113$. [CrossRef]

48. Perdue, C.W.; Dovidio, J.F.; Gurtman, M.B.; Tyler, R.B. Us and them: Social categorization and the process of intergroup bias. J. Personal. Soc. Psychol. 1990, 59, 475. [CrossRef]

49. Leudar, I.; Marsland, V. On membership categorization: 'us', 'them' and 'doing violence' in political discourse. Discourse Soc. 2004, 15, 243-266. [CrossRef]

50. Young, J. On Insiders (Emic) and Outsiders (Etic): Views of Self, and Othering. Syst. Pract. Action Res. 2005, 18, 151-162. [CrossRef]

51. Midgley, G.; Pinzón, L.A. Systemic mediation: Moral reasoning and boundaries of concern: Systemic mediation. Syst. Res. Behav. Sci. 2013, 30, 607-632. [CrossRef]

52. Bentley, S.V.; Greenaway, K.H.; Haslam, S.A. Cognition in context: Social inclusion attenuates the psychological boundary between self and other. J. Exp. Soc. Psychol. 2017, 73, 42-49. [CrossRef]

53. King, S.L.; Connor, R.C.; Krützen, M.; Allen, S.J. Cooperation-based concept formation in male bottlenose dolphins. Nat. Commun. 2021, 12, 2373. [CrossRef]

54. Stafstrom, J.A.; Menda, G.; Nitzany, E.I.; Hebets, E.A.; Hoy, R.R. Ogre-Faced, Net-Casting Spiders Use Auditory Cues to Detect Airborne Prey. Curr. Biol. 2020, 30, 5033-5039.e3. [CrossRef]

55. Rubin, N. Figure and ground in the brain. Nat. Neurosci. 2001,4,857-858. [CrossRef]

56. Baylis, G.C.; Driver, J. Shape-coding in IT cells generalizes over contrast and mirror reversal, but not figure-ground reversal. Nat. Neurosci. 2001, 4, 937-942. [CrossRef]

57. Bateson, G. Form Substance and Difference. Essent. Readings Biosemiotics 1970, 501, 9.

58. Darwin, C. On the Origin of Species: By Means of Natural Selection, or The Preservation of Favoured Races in the Struggle for Life; John Murray: London, UK, 1859.

59. Bertalanffy, L. The history and status of general systems theory. Acad. Manag. J. 1972, 15, 407-426.

60. Rittel, H.W.J.; Webber, M.M. Dilemmas in a general theory of planning. Policy Sci. 1973, 4, 155-169. [CrossRef]

61. Marchal, J.H. On the Concept of a System. Philos. Sci. 1975, 42, 448-468. [CrossRef]

62. Goguen, J.A.; Varela, F.J. Systems And Distinctions: Duality And Complementarity. Int. J. Gen. Syst. 1979, 5, 31-43. [CrossRef]

63. Ivan, M.; Kondo, K.; Yang, H.; Kim, W.; Valiando, J.; Ohh, M.; Salic, A.; Asara, J.M.; Lane, W.S.; Kaelin, W.G., Jr. HIFa Targeted for VHL-Mediated Destruction by Proline Hydroxylation: Implications for O Sensing. Science 2001, 292, 464-468. [CrossRef]

64. Chen, P.; Fan, D.; Zhang, Y.; Selloni, A.; Carter, E.A.; Arnold, C.B.; Dankworth, D.C.; Rucker, S.P.; Chelikowsky, J.R.; Yao, N. Breaking a dative bond with mechanical forces. Nat. Commun. 2021, 12, 5635. [CrossRef]

65. Wadhams, G.H.; Armitage, J.P. Making sense of it all: Bacterial chemotaxis. Nat. Rev. Mol. Cell Biol. 2004, 5, 1024-1037. [CrossRef]

66. Janetopoulos, C.; Firtel, R.A. Directional sensing during chemotaxis. FEBS Lett. 2008, 582, 2075-2085. [CrossRef]

67. Ikeya, N.; Woodward, J.R. Cellular autofluorescence is magnetic field sensitive. Proc. Natl. Acad. Sci. USA 2021, 118, e2018043118. [CrossRef]

68. Förster, D.; Helmbrecht, T.O.; Mearns, D.S.; Jordan, L.; Mokayes, N.; Baier, H. Retinotectal circuitry of larval zebrafish is adapted to detection and pursuit of prey. Elife 2020, 9, e58596. [CrossRef] [PubMed]

69. De Corte, B.J.; Navarro, V.M.; Wasserman, E.A. Non-cortical magnitude coding of space and time by pigeons. Curr. Biol. 2017, 27, R1264-R1265. [CrossRef] [PubMed]

70. Schnell, A.K.; Loconsole, M.; Garcia-Pelegrin, E.; Wilkins, C.; Clayton, N.S. Jays are sensitive to cognitive illusions. R. Soc. Open Sci. 2021, 8, 202358. [CrossRef] [PubMed]

71. Giannoni-Guzmán, M.A.; Rivera, E.; Aleman-Rios, J.; Melendez Moreno, A.M.; Ramos, M.P.; Pérez-Claudio, E.; Loubriel, D.; Moore, D.; Giray, T.; Agosto-Rivera, J.L. The Role of Colony Temperature in the Entrainment of Circadian Rhythms of Honey Bee Foragers. Ann. Entomol. Soc. Am. 2021, 114, 596-605. [CrossRef] [PubMed] 
72. Mareschal, D.; Quinn, P.C. Categorization in infancy. Trends Cogn. Sci. 2001, 5, 443-450. [CrossRef]

73. Ashby, F.G.; Ell, S.W.; Waldron, E.M. Procedural learning in perceptual categorization. Mem. Cogn. 2003, 31, 1114-1125. [CrossRef] [PubMed]

74. Sloutsky, V.M. The role of similarity in the development of categorization. Trends Cogn. Sci. 2003, 7, 246-251. [CrossRef]

75. Lewis, M.; Balamurugan, A.; Zheng, B.; Lupyan, G. Characterizing Variability in Shared Meaning through Millions of Sketches. Proc. Annu. Meet. Cognit. Sci. Soc. 2021, 43.

76. Lewandowsky, S.; Roberts, L.; Yang, L.X. Knowledge partitioning in categorization: Boundary conditions. Mem. Cogn. 2006, 34, 1676-1688. [CrossRef]

77. Sperry, R.W. Cerebral Organization and Behavior: The split brain behaves in many respects like two separate brains, providing new research possibilities. Science 1961, 133, 1749-1757. [CrossRef]

78. Lupyan, G. The conceptual grouping effect: Categories matter (and named categories matter more). Cognition 2008, 108, 566-577. [CrossRef] [PubMed]

79. Van Dijk, J.; Kerkhofs, R.; van Rooij, I.; Haselager, P. Special Section: Can There Be Such a Thing as Embodied Embedded Cognitive Neuroscience? Theory Psychol. 2008, 18, 297-316. [CrossRef]

80. Mahon, B.Z.; Caramazza, A. Concepts and categories: A cognitive neuropsychological perspective. Annu. Rev. Psychol. 2009, 60, 27-51. [CrossRef] [PubMed]

81. Cira, N.J.; Benusiglio, A.; Prakash, M. Vapour-mediated sensing and motility in two-component droplets. Nature 2015, 519, 446-450. [CrossRef] [PubMed]

82. Tweedy, L.; Thomason, P.A.; Paschke, P.I.; Martin, K.; Machesky, L.M.; Zagnoni, M.; Insall, R.H. Seeing around corners: Cells solve mazes and respond at a distance using attractant breakdown. Science 2020, 369, eaay9792. [CrossRef] [PubMed]

83. Blackiston, D.; Lederer, E.; Kriegman, S.; Garnier, S.; Bongard, J.; Levin, M. A cellular platform for the development of synthetic living machines. Sci. Robot. 2021, 6, eabf1571. [CrossRef] [PubMed]

84. Tarrant, M.; Calitri, R.; Weston, D. Social identification structures the effects of perspective taking. Psychol. Sci. 2012, 23, 973-978. [CrossRef]

85. Takaoka, A.; Maeda, T.; Hori, Y.; Fujita, K. Do dogs follow behavioral cues from an unreliable human? Anim. Cogn. 2015, 18, 475-483. [CrossRef]

86. Havy, M.; Waxman, S.R. Naming influences 9-month-olds' identification of discrete categories along a perceptual continuum Cognition 2016, 156, 41-51. [CrossRef]

87. Mischel, W.; Ebbesen, E.B. Attention in delay of gratification. J. Pers. Soc. Psychol. 1970, 16, 329-337. [CrossRef]

88. Schnell, A.K.; Boeckle, M.; Rivera, M.; Clayton, N.S.; Hanlon, R.T. Cuttlefish exert self-control in a delay of gratification task. Proc. Biol. Sci. 2021, 288, 20203161. [CrossRef] [PubMed]

89. Boisseau, R.P.; Vogel, D.; Dussutour, A. Habituation in non-neural organisms: Evidence from slime moulds. Proc. Biol. Sci. 2016, 283, 20160446. [CrossRef] [PubMed]

90. Cabrera, D.; Cabrera, L.; Powers, E. A Unifying Theory of Systems Thinking with Psychosocial Applications. Syst. Res. 2015, 32, 534-545. [CrossRef]

91. Simon, H.A. The Architecture of Complexity. Proc. Am. Philos. Soc. 1962, 106, 467-482.

92. Anderson, J.R. The adaptive nature of human categorization. Psychol. Rev. 1991, 98, 409. [CrossRef]

93. Di Pellegrino, G. Categorization in single neurons. Trends Cogn. Sci. 2001, 5, 186. [CrossRef]

94. Muehlhaus, J.; Heim, S.; Altenbach, F.; Chatterjee, A.; Habel, U.; Sass, K. Deeper insights into semantic relations: An fMRI study of part-whole and functional associations. Brain Lang. 2014, 129, 30-42. [CrossRef]

95. Montoro, P.R.; Luna, D.; Ortells, J.J. Subliminal Gestalt grouping: Evidence of perceptual grouping by proximity and similarity in absence of conscious perception. Conscious. Cogn. 2014, 25, 1-8. [CrossRef]

96. Baron-Cohen, S.; Ashwin, E.; Ashwin, C.; Tavassoli, T.; Chakrabarti, B. Talent in autism: Hyper-systemizing, hyper-attention to detail and sensory hypersensitivity. Philos. Trans. R. Soc. Lond. B Biol. Sci. 2009, 364, 1377-1383. [CrossRef]

97. Lewin, K. Dynamic Theory of Personality; Read Books Ltd.: Redditch, UK, 1935.

98. Mooney, R.L. Perception, language, and the part-whole problem. In Psychology of Reading; Garrard Press: New York, NY, USA, 1951.

99. Ackoff, R.L. Towards a System of Systems Concepts. Manag. Sci. 1971, 17, 661-671. [CrossRef]

100. Solomon, K.O.; Medin, D.L.; Lynch, E. Concepts do more than categorize. Trends Cogn. Sci. 1999, 3, 99-105. [CrossRef]

101. Tversky, B.; Hemenway, K. Objects, parts, and categories. J. Exp. Psychol. Gen. 1984, 113, 169. [CrossRef] [PubMed]

102. Glushko, R.J.; Maglio, P.P.; Matlock, T.; Barsalou, L.W. Categorization in the wild. Trends Cogn. Sci. 2008, 12, 129-135. [CrossRef] [PubMed]

103. Liberman, Z.; Woodward, A.L.; Kinzler, K.D. The Origins of Social Categorization. Trends Cogn. Sci. 2017, 21, 556-568. [CrossRef]

104. Fisher, M.; Keil, F.C. The Binary Bias: A Systematic Distortion in the Integration of Information. Psychol. Sci. 2018, 29, 1846-1858. [CrossRef]

105. Kominsky, J.F.; Strickland, B.; Wertz, A.E.; Elsner, C.; Wynn, K.; Keil, F.C. Categories and Constraints in Causal Perception. Psychol. Sci. 2017, 28, 1649-1662. [CrossRef]

106. Weily, J. Review of Cybernetics or Control and Communication in the Animal and the Machine. Psychol. Bull. 1951, 46, 236-237.

107. Wiener, N. Cybernetics or Control and Communication in the Animal and the Machine; MIT Press: Cambridge, MA, USA, 1961. 
108. Clement, C.A.; Falmagne, R.J. Logical reasoning, world knowledge, and mental imagery: Interconnections in cognitive processes. Mem. Cogn. 1986, 24, 299-307. [CrossRef]

109. Gopnik, A.; Glymour, C.; Sobel, D.M.; Schulz, L.E.; Kushnir, T.; Danks, D. A theory of causal learning in children: Causal maps and Bayes nets. Psychol. Rev. 2004, 111, 3-32. [CrossRef]

110. Schulz, L.E.; Gopnik, A. Causal learning across domains. Dev. Psychol. 2004, 40, 162-176. [CrossRef]

111. Greene, A.J. Making Connections. Sci. Am. Mind. 2010, 21, 22-29. [CrossRef]

112. Piao, Y.; Yao, G.; Jiang, H.; Huang, S.; Huang, F.; Tang, Y.; Liu, Y.; Chen, Q. Do pit vipers assess their venom? Defensive tactics of Deinagkistrodon acutus shift with changed venom reserve. Toxicon 2021, 199, 101-108. [CrossRef] [PubMed]

113. Chersi, F.; Ferro, M.; Pezzulo, G.; Pirrelli, V. Topological self-organization and prediction learning support both action and lexical chains in the brain. Top. Cogn. Sci. 2014, 6, 476-491. [CrossRef] [PubMed]

114. Ferry, A.L.; Hespos, S.J.; Gentner, D. Prelinguistic Relational Concepts: Investigating Analogical Processing in Infants. Child Dev. 2015, 86, 1386-1405. [CrossRef] [PubMed]

115. Harris, P.L.; German, T.; Mills, P. Children's use of counterfactual thinking in causal reasoning. Cognition 1996, 61, 233-259. [CrossRef]

116. Mascalzoni, E.; Regolin, L.; Vallortigara, G.; Simion, F. The cradle of causal reasoning: Newborns preference for physical causality Dev. Sci. 2013, 16, 327-335. [CrossRef] [PubMed]

117. Rolfs, M.; Dambacher, M.; Cavanagh, P. Visual adaptation of the perception of causality. Curr. Biol. 2013, 23, 250-254. [CrossRef]

118. Dhamala, M. What is the nature of causality in the brain?-Inherently probabilistic: Comment on "Foundational perspectives on causality in large-scale brain networks" by M. Mannino and S.L. Bressler. Phys. Life Rev. 2015, 15, 139-140. [CrossRef]

119. Sanefuji, W.; Haryu, E. Preschoolers' Development of Theory of Mind: The Contribution of Understanding Psychological Causality in Stories. Front. Psychol. 2018, 9, 955. [CrossRef]

120. Cabrera, D.; Cabrera, L.; Cabrera, E. An Ecology of Studies on Action-Reaction Relationships: Research into Universals of Systems Thinking and Cognitive Complexity in Mind and Nature. J. Syst. Think. 2021, 10, 21.

121. Marvin, R.S.; Greenberg, M.T.; Mossler, D.G. The Early Development of Conceptual Perspective Taking: Distinguishing among Multiple Perspectives. Child Dev. 1976, 47, 511-514. [CrossRef]

122. Premack, D.; Woodruff, G. Does the chimpanzee have a theory of mind? Behav. Brain Sci. 1978, 1, 515-526. [CrossRef]

123. Endler, J.A. Bowerbirds, art and aesthetics: Are bowerbirds artists and do they have an aesthetic sense? Commun. Integr. Biol. 2012, 5, 281-283. [CrossRef]

124. Thomas, B. Ravens attribute visual access to unseen competitors. Nat. Commun. 2016, 7, 1-6.

125. Chamovitz, D. What a Plant Knows: A Field Guide to the Senses. Plant Prot. Q. 2012, 27, 116.

126. Montesinos-Navarro, A.; Storer, I.; Perez-Barrales, R. Benefits for nurse and facilitated plants emerge when interactions are considered along the entire life-span. Perspect. Plant Ecol. Evol. Syst. 2019, 41, 125483. [CrossRef]

127. Baron-Cohen, S.; Leslie, A.M.; Frith, U. Does the autistic child have a "theory of mind"? Cognition 1985, 21, 37-46. [CrossRef]

128. Vallar, G.; Lobel, E.; Galati, G.; Berthoz, A.; Pizzamiglio, L.; Le Bihan, D. A fronto-parietal system for computing the egocentric spatial frame of reference in humans. Exp. Brain Res. 1999, 124, 281-286. [CrossRef]

129. Dyson, F. Disturbing the Universe; Basic Books Inc.: New York, NY, USA, 1979.

130. Zwick, A.; Álvarez, G.A.; Kurizki, G. Maximizing Information on the Environment by Dynamically Controlled Qubit Probes. Phys. Rev. Applied 2016, 5, 014007. [CrossRef]

131. Álvarez, G.A. Email To Cabrera: “RE: Question about Your Article on Qubit Probes"; 2021. Available online: https://tinyurl com/4876tv64 (accessed on 15 November 2021).

132. Ruby, P.; Decety, J. How would you feel versus how do you think she would feel? A neuroimaging study of perspective-taking with social emotions. J. Cogn. Neurosci. 2004, 16, 988-999. [CrossRef]

133. Russell, J.; Alexis, D.; Clayton, N. Episodic future thinking in 3- to 5-year-old children: The ability to think of what will be needed from a different point of view. Cognition 2010, 114, 56-71. [CrossRef] [PubMed]

134. Rakoczy, H.; Wandt, R.; Thomas, S.; Nowak, J.; Kunzmann, U. Theory of mind and wisdom: The development of different forms of perspective-taking in late adulthood. Br. J. Psychol. 2018, 109, 6-24. [CrossRef] [PubMed]

135. Mafessoni, F.; Lachmann, M. The complexity of understanding others as the evolutionary origin of empathy and emotional contagion. Sci. Rep. 2019, 9, 5794. [CrossRef] [PubMed]

136. Tversky, A.; Kahneman, D. The Framing of Decisions and the Psychology of Choice. In Behavioral Decision Making; Springer: Boston, MA, USA, 1985

137. Schober, M.F. Spatial perspective-taking in conversation. Cognition 1993, 47, 1-24. [CrossRef]

138. Bateson, G. Perspective Taking: Imagining how another would feel versus imagining how you would feel. Personal. Soc. Psychol. Bull. 1997, 23, 751-758. [CrossRef]

139. Knowles, M.L. Social rejection increases perspective taking. J. Exp. Soc. Psychol. 2014, 55, 126-132. [CrossRef]

140. Cavallo, A.; Ansuini, C.; Capozzi, F.; Tversky, B.; Becchio, C. When Far Becomes Near. Psychol. Sci. 2017, 28, 69-79. [CrossRef]

141. Neale, M.A.; Bazerman, M.H. The Role of Perspective-Taking Ability in Negotiating under Different Forms of Arbitration. ILR Rev. 1983, 36, 378-388. [CrossRef]

142. Galinsky, A.D.; Moskowitz, G.B. Perspective-taking: Decreasing stereotype expression, stereotype accessibility, and in-group favoritism. J. Pers. Soc. Psychol. 2000, 78, 708-724. [CrossRef] 
143. Takaku, S.; Weiner, B.; Ohbuchi, K.I. A cross-cultural examination of the effects of apology and perspective taking on forgiveness. J. Lang. Soc. Psychol. 2001, 20, 144-166. [CrossRef]

144. Parker, S.K.; Axtell, C.M. Seeing Another Viewpoint: Antecedents and Outcomes of Employee Perspective Taking. Acad. Manag. J. 2001, 44, 1085-1100.

145. Epley, N.; Keysar, B.; Van Boven, L.; Gilovich, T. Perspective taking as egocentric anchoring and adjustment. J. Pers. Soc. Psychol. 2004, 87, 327-339. [CrossRef] [PubMed]

146. Davis, M.H.; Soderlund, T.; Cole, J.; Gadol, E.; Kute, M.; Myers, M.; Weihing, J. Cognitions associated with attempts to empathize: How do we imagine the perspective of another? Pers. Soc. Psychol. Bull. 2004, 30, 1625-1635. [CrossRef]

147. Harwood, M.D.; Farrar, M.J. Conflicting emotions: The connection between affective perspective taking and theory of mind. Br. J. Dev. Psychol. 2006, 24, 401-418. [CrossRef]

148. Tversky, B.; Hard, B.M. Embodied and disembodied cognition: Spatial perspective-taking. Cognition 2009, 110, 124-129. [CrossRef] [PubMed]

149. Wang, C.S.; Tai, K.; Ku, G.; Galinsky, A.D.; Urgesi, C. Perspective-Taking Increases Willingness to Engage in Intergroup Contact. PLoS ONE 2014, 9, e85681. [CrossRef]

150. Ben-Ami Bartal, I.; Decety, J.; Mason, P. Empathy and pro-social behavior in rats. Science 2011, 334, 1427-1430. [CrossRef]

151. Satoh, S.; Bshary, R.; Shibasaki, M.; Inaba, S.; Sogawa, S.; Hotta, T.; Awata, S.; Kohda, M. Prosocial and antisocial choices in a monogamous cichlid with biparental care. Nat. Commun. 2021, 12, 1775. [CrossRef]

152. Gagliano, M.; Renton, M.; Depczynski, M.; Mancuso, S. Experience teaches plants to learn faster and forget slower in environments where it matters. Oecologia 2014, 175, 63-72. [CrossRef]

153. Gagliano, M. Inside the Vegetal Mind: On the Cognitive Abilities of Plants. In Memory and Learning in Plants; Baluska, F., Gagliano, M., Witzany, G., Eds.; Springer International Publishing: Cham, Switzerland, 2018; pp. 215-220.

154. Cabrera, L.; Cabrera, D. Systems Thinking \& Metacognition Inventory (STMI): A Validated Test of Systems Thinking. In The Routledge Handbook for Systems Thinking; Cabrera, L., Cabrera, D., Midgley, G., Eds.; Routledge Press: London, UK, 2021.

155. Fleming, S.M. Metacognition Is the Forgotten Secret to Success Insight into Our Own Thoughts, or Metacognition, Is Key to High Achievement in All Domains; Scientific American Mind: New York, NY, USA, 2014.

156. Flavell, J.H. Metacognition and cognitive monitoring: A new area of cognitive-developmental inquiry. Am. Psychol. 1979, 34, 906-911. [CrossRef]

157. Flavell, J.H. Metacognitive Aspects of Problem Solving. In The Nature of Intelligence; Resnick, L.B., Ed.; Erlbaum: Hillsdale, NJ, USA, 1976; pp. 231-236.

158. Piaget, J. The Psychology of Intelligence; Routledge: London, UK, 1950.

159. Akturk, A.O.; Sahin, I. Literature Review on Metacognition and its Measurement. Procedia Soc. Behav. Sci. 2011, 15, 3731-3736. [CrossRef]

160. Lewis, M.L.; Frank, M.C. The length of words reflects their conceptual complexity. Cognition 2016, 153, 182-195. [CrossRef] [PubMed]

161. De Brey, C.; Musu, L.; McFarland, J. Status and Trends in the Education of Racial and Ethnic Groups 2018; National Center for Education Statistics: Washington, DC, USA, 2018.

162. Aud, S.; Fox, M.A.; KewalRamani, A. Status and Trends in the Education of Racial and Ethnic Groups; National Center for Education Statistics: Washington, DC, USA, 2010. 